SANDIA REPORT SAND81-2199 • Unlimited Release • UC-35

Printed June 1982

\title{
Effects of Particle Characteristics on Performance of RR5K PETN
}

J. W. Rogers, Jr., and A. A. Duncan

\section{Prepared by}

Sandia National Laboratories

Albuquerque, New Mexico 87185 and Livermore, California 94550

for the United States Department of Energy

under Contract DE-AC04-76DP00789.

When printing a copy of any digitized SAND Report, you are required to update the markings to current standards. 
Issued by Sandia National Laboratories, operated for the Unitod States Department of Energy by Sandia Corporation.

NOTICE: This report was prepared as an account of work sponsored by an agency of the United States Government. Neither the United States Government nor any agency thereof, nor any of their employees, nor any of their contractors, subcontractors, or their employees, makes any warranty, express or implied, or assumes any legal liability or responsibility for the accuracy, completeness, or usefulness of any information, apparatus, product, or process disclosed, or represents that its use would not infringe privately owned rights. Reference herein to any specific commercial product, process, or rights. Reference herein to any specific commercial product, process, or necessarily constitute or imply its endorsement, recommendation, or favoring by the United States Government, any agency thereof or any of their contractors or subcontractors. The views and opinions expressed herein do not necessarily state or reflect those of the United States Government, any agency thereof or any of their contractors or subcontractors.

Printed in the United States of America

Available from

National Technical Information Service

U.S. Department of Commerce

5285 Port Royal Road

Springfield, VA 22161

NTIS price codes

Printed copy: A04

Microfiche copy: A01 
SAND 81- 2199

UC -35

Unlimited Release

\title{
EFFECTS OF PARTICLE CHARACTERISTICS
}

ON PERFORMANCE OF RR5K PETN*

J. W. Rogers, Jr.

Explosive Materials Division 2516

Sandia National Laboratories

A1buquerque, New Mexico 87185

and

A. A. Duncan

Development Division

Mason \& Hanger - Silas Mason Co., Inc.

Pantex Plant P. 0. Box 30020

Amari11o, Texas 79177

\begin{abstract}
A particle characterization of production lots of RR5K PETN has been completed. Prediction models were derived which identify those particle characteristics which influence sensitivity and performance. Those factors which have a positive influence on threshold burst current were also found to have a positive influence on transit time. The models may be useful in screening new lots of PETN prior to test firing. In general, large distributions of shapes and sizes, with the larger particles being needle-like or elongated, lead to low threshold burst currents and short transit times. The threshold burst current was also found to be inversely proportional to the temperature at which the units were test fired.
\end{abstract}

${ }^{*}$ This work supported by the U.S. Department of Energy under contract DE-AC04-76DP00789. 


\section{ACKNOWLEDGEMENT}

We wish to thank L. Garrett and R. Skelton for help in obtaining the data, R. J. Burnett and C. R. Clark for helpful discussions, and Francine Singleton for typing the manuscript. 


\section{CONTENTS}

$\underline{\text { Page }}$

I. Introduction $\quad 7$

II. Experimental $\quad 8$

III. Results and Discussion 13

IV. Summary and Conclusions 36

$\begin{array}{ll}\text { References } & 38\end{array}$

$\begin{array}{ll}\text { Appendix I } & 39\end{array}$

$\begin{array}{ll}\text { Appendix II } & 49\end{array}$

$\begin{array}{ll}\text { Appendix III } & 55\end{array}$

$\begin{array}{ll}\text { Appendix IV } & 56\end{array}$ 
Table 1 List of Measured and Calculated Particle Characteristics

Table 2 RR5K PETN Test Fire Data

Table 3 Simple Linear Correlation Coefficients Involving RR5K PETN Performance

Table 4 Prediction Mode1s for RR5K PETN

$\begin{array}{lll}\text { Figure } 1 & \text { Threshold Burst Current vs. Temperature } & 15\end{array}$

Figure 2 Maximum Transit Time vs. Temperațure 16

$\begin{array}{llr}\text { Figure } 3 & \text { Minimum Transit Time vs. Temperature } & 17\end{array}$

Figure 4 Threshold Burst Current vs. Year of Recrystallization 19

Figure 5 Threshold Burst Current vs. Temperature of Test and Year of Recrystallization

Figure 6 Transit Time for Screen Data vs. Year of Recrystal1ization 21

Figure 7 Transit Time at $+700 \mathrm{~F}$ vs. Year of Recrysta11ization 22

Figure 8 Transit Time at $-650 \mathrm{~F}$ vs. Year of Recrysta1lization 23

Figure 9 Transit Time at $+1600 \mathrm{~F}$ vs. Year of Recrystallization 24

Figure 10 Range of Transit Times vs. Year of Recrystallization 26

Figure 11 Threshold Burst Current vs. Maximum Transit Time 27

Figure 12 Threshold Burst Current vs. Minimum Transit Time 28

Figure 13 Maximum vs. Minimum Transit Time 29

Figure 14 Standard Deviation of Threshold vs. Transit Time Range 31

$\begin{array}{lll}\text { Figure I-1 RR5K PETN Lot } 1201 & 40\end{array}$

Figure I-2 RR5K PETN Lot 1159

Figure I-3 RR5K PETN Lot 1204

Figure I-4 RR5K PETN Lot 1206

Figure I-5 RR5K PETN Lot 1258

Figure I-6 RR5K PETN Lot 1375 
Figure I-7 RR5K PETN Lot 1376

Figure I-8 RR5K PETN Lot 1377

Figure I-9 RR5K PETN Lot $1378 \quad 48$

Figure II-1 Porosity vs. Sample Weight 50

Figure II-2 Surface Area vs. Samp1e Weight 51

Figure II-3 Average Diameter vs. Sample Weight 52

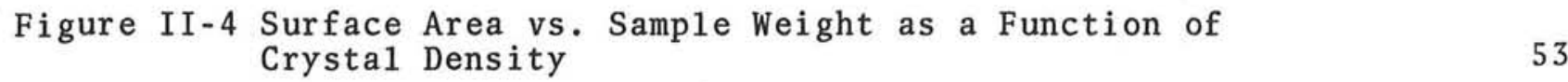

Figure II-5 Surface Area vs. Porosity 


\section{Introduction}

Production lots of RR5K PETN (pentaerythritol tetranitrate) are qualified by Fisher sub-sieve sizer (FSSS) surface area determination and test firing in standard exploding wire detonators. Lots having passed the,FSSS specification $\left(5000 \pm 300 \mathrm{~cm}^{2} / \mathrm{g}\right)$ have failed to test fire as specified. This study was designed to better understand which particle characteristics influence explosive sensitivity and performance.

The test firing determined threshold burst current, transit times, and their variations. The tests were carried out over the temperature range -65 of to +160 of in units which had been subjected to various environments (mechanical shock, vibration, thermal cycling). The correlations between the test fire results, obtained from simple linear regression, are presented.

A particle characterization of all nine production lots, manufactured over the past fifteen years, has been completed and includes surface areas from FSSS analysis, dynamic flow gas adsorption isotherms derived from the Brunauer-Emmet-Teller (BET) equation, and optical microscopy analysis using a Zeiss analyzer. These data were correlated with the original performance results using factor analysis and linear stepwise regression. Prediction models were derived to better understand those variables which influence threshold burst current and function time. In most cases, the models were limited to two particle variables due to the limited number of PETN lots observed. The results and a discussion of why particular variables influence performance are presented. 


\section{Experimenta1}

\section{A. Performance Testing}

The RR5K PETN (hereafter called PETN) was originally qualified by meeting a FSSS surface area specification of $5000 \pm$ $300 \mathrm{~cm}^{2} / \mathrm{g}$ and by test firing in standard exploding wire detonators. Threshold bridgewire burst current $\left(\mathrm{I}_{\mathrm{bth}}\right)$, the current at which 50 percent of the units fired high order, and minimum and maximum function time $\left(t_{e}\right)$, the time from maximum bridgewire voltage to start of pulse switch output, were recorded. The transit time measurements were conducted at a current greater than twice the threshold burst current. Threshold burst current was determined by the Bruceton method followed by ASENT [1] analysis and a steel dent block was used to detect high-order detonations (a dent $>0.004 " \equiv$ high order). The test fire matrix included: (1) screening tests of units held at 1900F/30 hours (or $1600 \mathrm{~F} / 1$ week) and fired at $-650 \mathrm{~F}$; (2) units subjected to no environment and tested at $700 \mathrm{~F}$; (3) units which were thermal cycled, vibrated and mechanically shocked at $-65^{\circ} \mathrm{F}$ and fired at $160^{\circ} \mathrm{F}$.

\section{B. Particle Characterization}

Particle characteristics of the PETN were measured by FSSS gas permeametry, dynamic flow BET gas adsorption, and Zeiss analysis.

\section{Fisher sub-sieve sizer.}

The FSSS method measures the resistance to air flow of a packed powder sample and compares this to flow through a standardized capillary. The mean particle surface-volume 
diameter [2] and specific surface area are then computed. Experimenta11y 1.766 grams of PETN is placed in a tube and compacted to a known porosity. (The mass used is numerically equal to the crystal density, $1.766 \mathrm{Mg} / \mathrm{m}^{3}$, for ease in data reduction.) The pressure drop across the bed is recorded; from this the mean surface-volume diameter and surface area are computed. The measured sample surface area and diameter vary with porosity for two reasons. Until the bed is uniformly packed, air will pass more readily around the aggregates than through them, and brittle crystals such as PETN will shatter at low porosity, increasing the exposed surface area. To facilitate comparison of surface areas from different lots of PETN, the particle diameters and surface areas are reported at a common porosity of 0.468 .

The FSSS method has an advantage over other methods of surface area measurements because the powders are compressed to densities comparable to those used in detonators giving measured surface areas (or particle diameters) similar to those expected from the environment in which the explosive will ultimately be used. A major disadvantage is that the method is not sensitive to reentrant surfaces. Reproducibility is good so long as a given operating procedure is strictly followed but slight differences in operating procedures can lead to significant variation in the final results as is discussed in Appendix II. Each lot of PETN was analyzed in duplicate, and the results are reported in Appendix III. 
2. Dynamic Flow BET.

The standard BET experiment requires degassing the sample in hard vacuum. Since PETN readily sublimes under these conditions, a dynamic flow BET method (Perkin Elmer She11 Mode1 212C Sorptometer) was used to measure the surface area by gas adsorption. In this method, a known mixture of nitrogen and helium is passed through one side of a conductive cell, then through a packed bed of explosive, and then into the other side of a thermal conductivity cell connected to a recording potentiometer. Upon cooling the powder to liquid nitrogen temperature, it adsorbs an amount of nitrogen proportional to its specific surface area. In this manner, surface areas can he determined to a relative reproducibility of better than 4 percent. Each lot of PETN was analyzed in duplicate and the average values are reported in Appendix III.

\section{Zeiss Analysis}

This is an optical microscopy method of measuring particle parameters. A representative PETN sample is carefully prepared on a glass slide to insure good dispersion of particles and that each particle is oriented with its smallest axis perpendicular to the slide. Photographs are taken at various magnifications from which the length and width (for rectangular particles such as PETN) of each particle in the photograph is measured with a Model TGZ-3 Automatic Zeiss Analyzer. The photographs for each lot are shown in Appendix I. Each particle is grouped into one of six shapes [3] and a geometric surface area and volume are calculated. The 
geometric areas and volumes will usually be less than the actual values because surface roughness and variation in shape cannot be included in the calculation. The height of a particle is determined by focusing on the top and bottom of the particle with a microscope and reading the distance the stage moved, using a micrometer. Many such measurements have shown that PETN has a constant height/width ratio of 0.85 . Thus, the height of each particle,was estimated from the measured width.

In the present study, 2000 particles per PETN lot were measured to insure adequate statistics for a representative sample distribution. From these measurements, 501 variables per lot of PETN were obtained and are summarized in Table 1. C. Data Analysis

The independent variables summarized in Table 1 were input into a Factor Analysis [4] program to determine which of the variables were inter-correlated (not independent). The program groups the variables into several factors, each of which contains intercorrelated variables. One or two variables were chosen from each factor for each of $D$ through $M$ in Table 1 . This reduced the number of independent variables to less than 50. Each of these independent variables was input to a Linear Stepwise Regression Program [5], along with the 20 dependent test fire variables $\left(I_{b t h}\left(+160^{\circ} \mathrm{F}\right), t_{e}\left(\max ,+160^{\circ} \mathrm{F}\right)\right.$, etc. $)$ for each lot of PETN. The regression was run separately for each dependent variable and prediction models were determined. Simple correlations were also determined among the test fire results and between the test 
Table 1

\section{List of Measured and Calculated Particle Characteristics}

\section{Measured Parameters for each Lor of PETN}

Fisher sub-sieve sizer (duplicate measurements)

A. Surface area (FSSS-SA)

B. Equivalent spherical diameter (FSSS-D)

Dynamic BET (duplicate measurements)

C. Surface area (GASADS)

Zeiss Analysis ( 2000 measurements per $10 t$ )

D. Length (LEN)

B. Width (WID)

Calculated Parameters per Particle (2000 particles/lot)

F. Length/width ratio (LWWR)

G. Cross-sectional area (CSA)

H. Surface area (SFA)

I. Volume (VOL)

J. Équivalent circular diameter (ECD)

K. Equivalent spherical diameter (ESD)

L. Degree of sphericity (DOS)

M. Harmonic mean diameter (HMD)

N. Zeiss specific surface area (ZSSA) (One calculated specific surface area per PETN lot.)

For items D-M distributions were obtained for each PBTN lot by frequency and weight. From each distribution, the following values were determined.

\section{Powder Limits}

1. Low value (Lo Val)

2. High value (Hi Val)

3. Range (Rng)

4. Mid-range (Mid Rng)

5. Mode (Mode)

\section{Distribution Means}

6. Arithmetic (A Mean)

7. Geometric (G Mean)

8. Harmonic (H Mean)

\section{Measurement of Dispersion}

Quartiles

9. Lower 25th (Qrt25)

10. Median'50th (Qrt50)

11. Upper 75th (Qrt75)

12. Percentile estimate (PctEst)

13. Semi-interquartile range (Semi-Qrt)

14. Kramer modulus (Kra Mod)

15. Median deviation (Med)

16. Low range from median (Lo Med)

17. High range from median (Hi Med)

Deviation and Variation

18. Standard deviation (Std Dev)

19. Variance (Var)

20. Coefficient of geometric (Co Geo Var) variation

21. Harmonic variation (Har Var)

22. Mean deviation (Mean Dev)

23. Low range from mean (Lo Mean)

24. High range from mean (Hi Mean)

This totals 504 possible independent variables per lot of PETN. The definition of each of these terms is included in Appendix IV.

\section{Measurement of distribution skewness}
25. Degree of synmetry
(Deg Sya)
26. Coefficient of skewness
(Co Skew)
27. Momental skewness
(Mo skew)
28. Kurtosis flatness
(Kurt)
29. Coefficient of excess
(Co Exs) 
fire results and temperature, date of recrystallization, and other environmental conditions.

Independent variables which appeared to show nonlinear behavior were analytically transformed into linear variables and input, to linear regression analysis. The transformed variables were rejected by the regression program after a few steps indicating that no improvement over linear correlations could be achieved hy considering nonlinear behavior.

III. Results and Discussion

\section{A. Performance Testing}

The test fire results for each lot of PETN are shown in Table 2. Included in the table are the powder specifications, year of production, and the environmental conditions prior to and temperature during testing.

\section{B. Effect of Temperature, Environment and Date of}

Recrystallization on Performance

To see how temperature, date of recrystallization, and thermal cycling and mechanical shock affect performance, each of these variables was linearly correlated with the test fire values. At a significance of 0.001 , the temperature is inversely related to $I_{b t h}$ as shown in Figure 1 . Interestingly, $t_{e}(\max )$ and $t_{e}(\min )$ are also inversely proportional to temperature. This behavior is shown in Figures 2 and 3 where $t_{e}(\max )$ and $t_{e}(\min )$ are plotted versus temperature.

Several effects could account for reduced transit times at higher temperatures. The ignition might occur at positions nearer the bridgewire at higher temperature. However the main 
Table 2. RR5K PETN TEST FIRE DATA

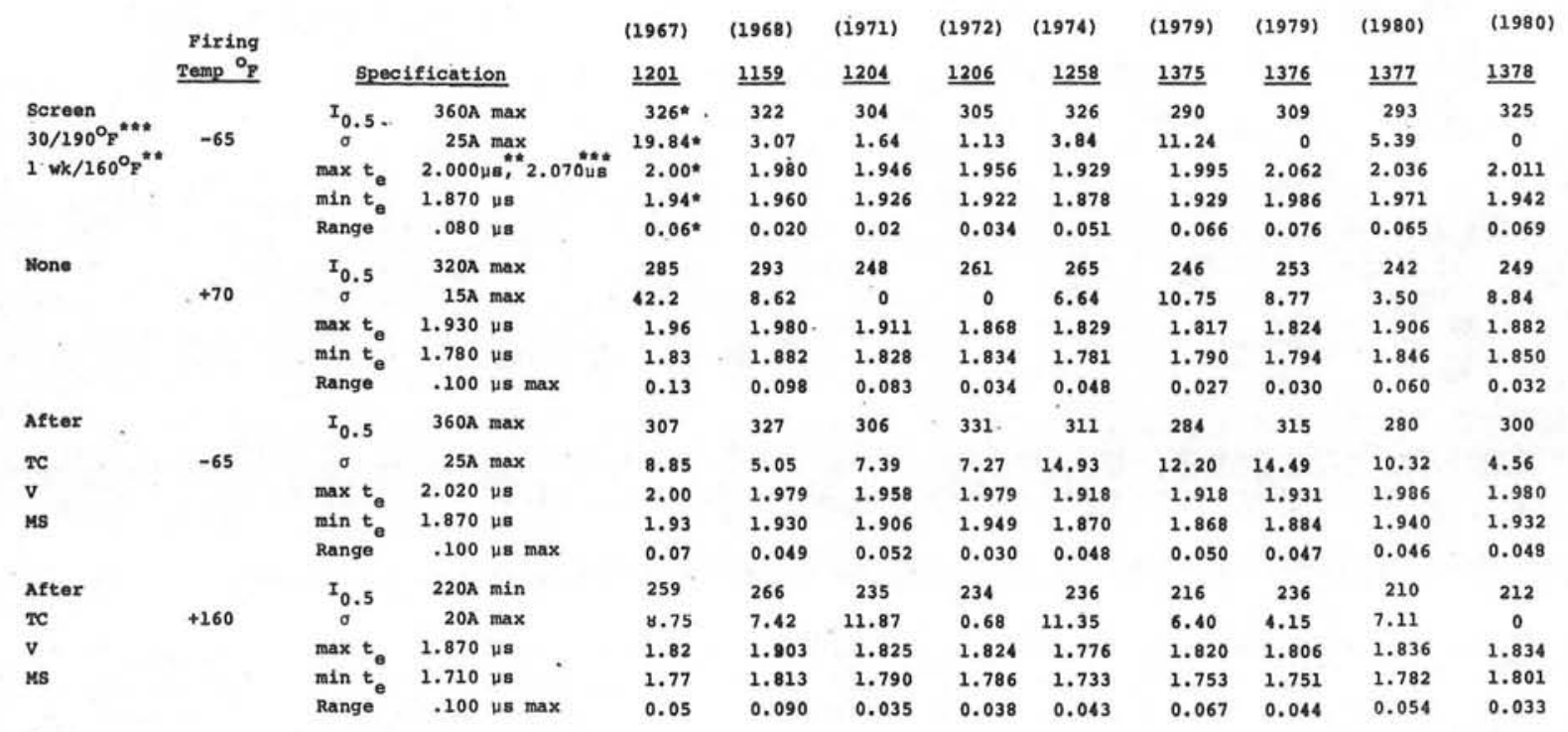

- Tested at sira

" priar to Lot 1375

Ail tests performed at Mound Facility except where indicated.

$\mathrm{TC} \equiv$ Thermal cycling

$\mathrm{v} \equiv$ vibration

MS $\equiv$ Mechanical Shock 


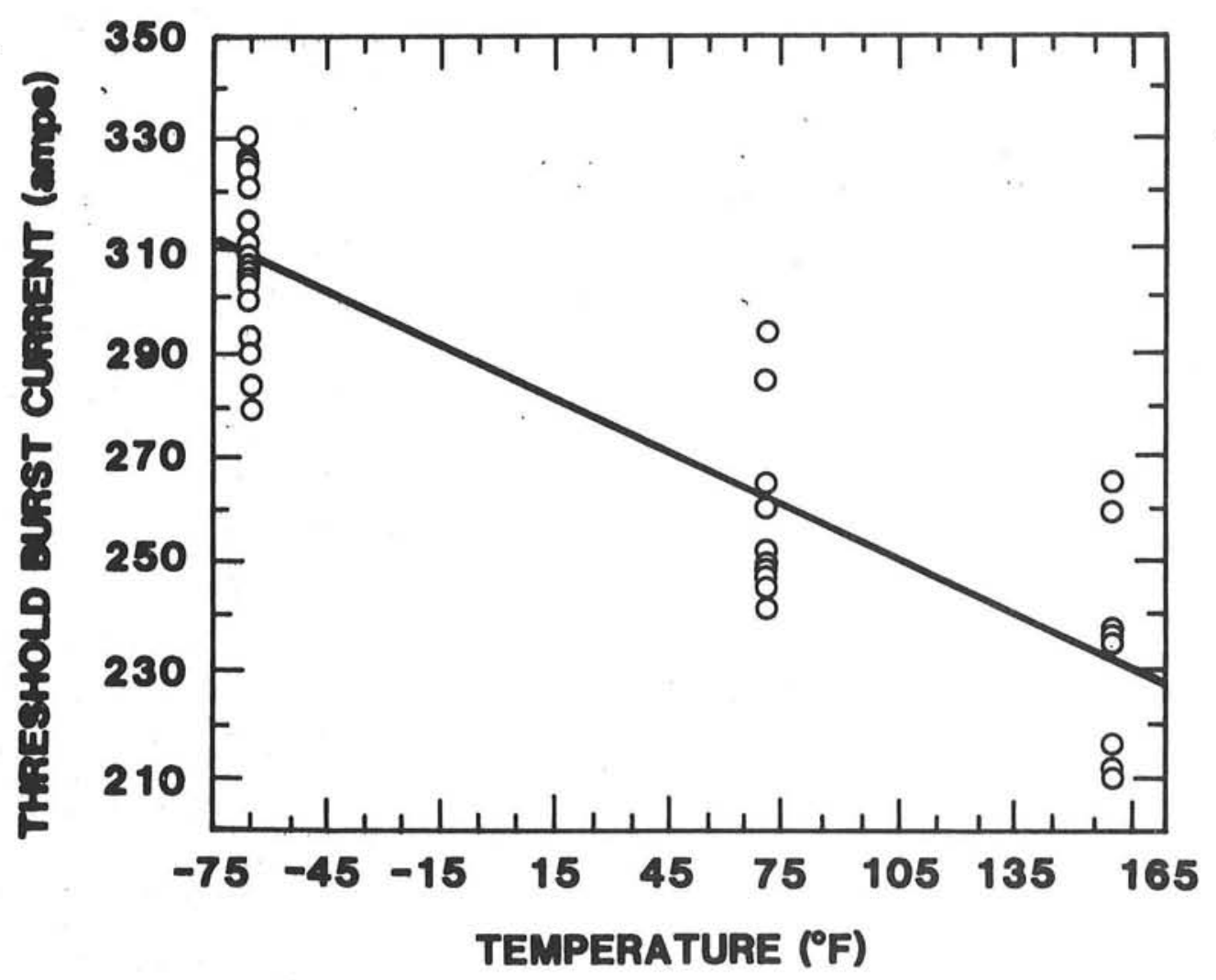

Figure 1. Threshold Burst Current vs. Temperature 


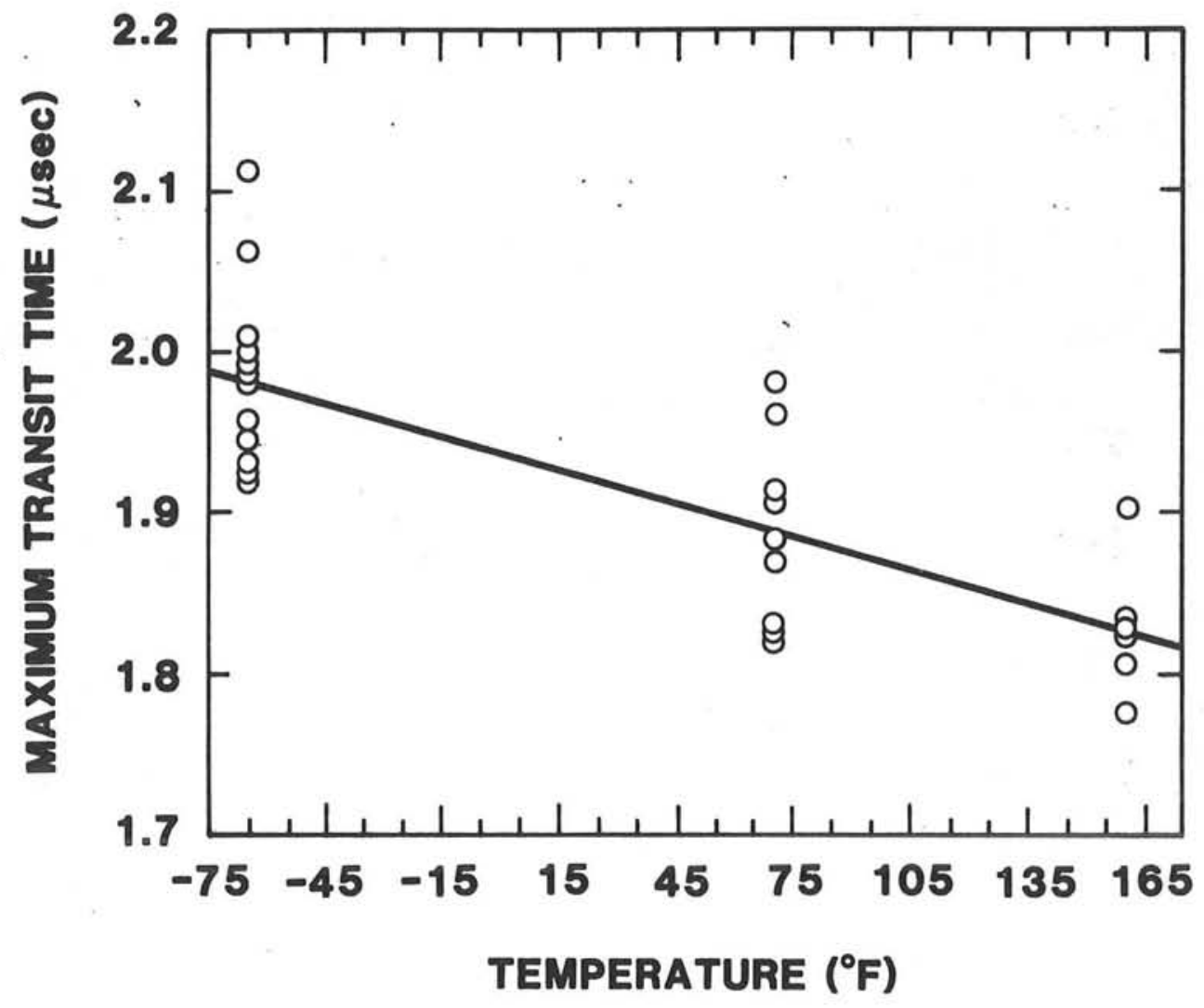

Figure 2. Maximum Transit Time vs. Temperature 


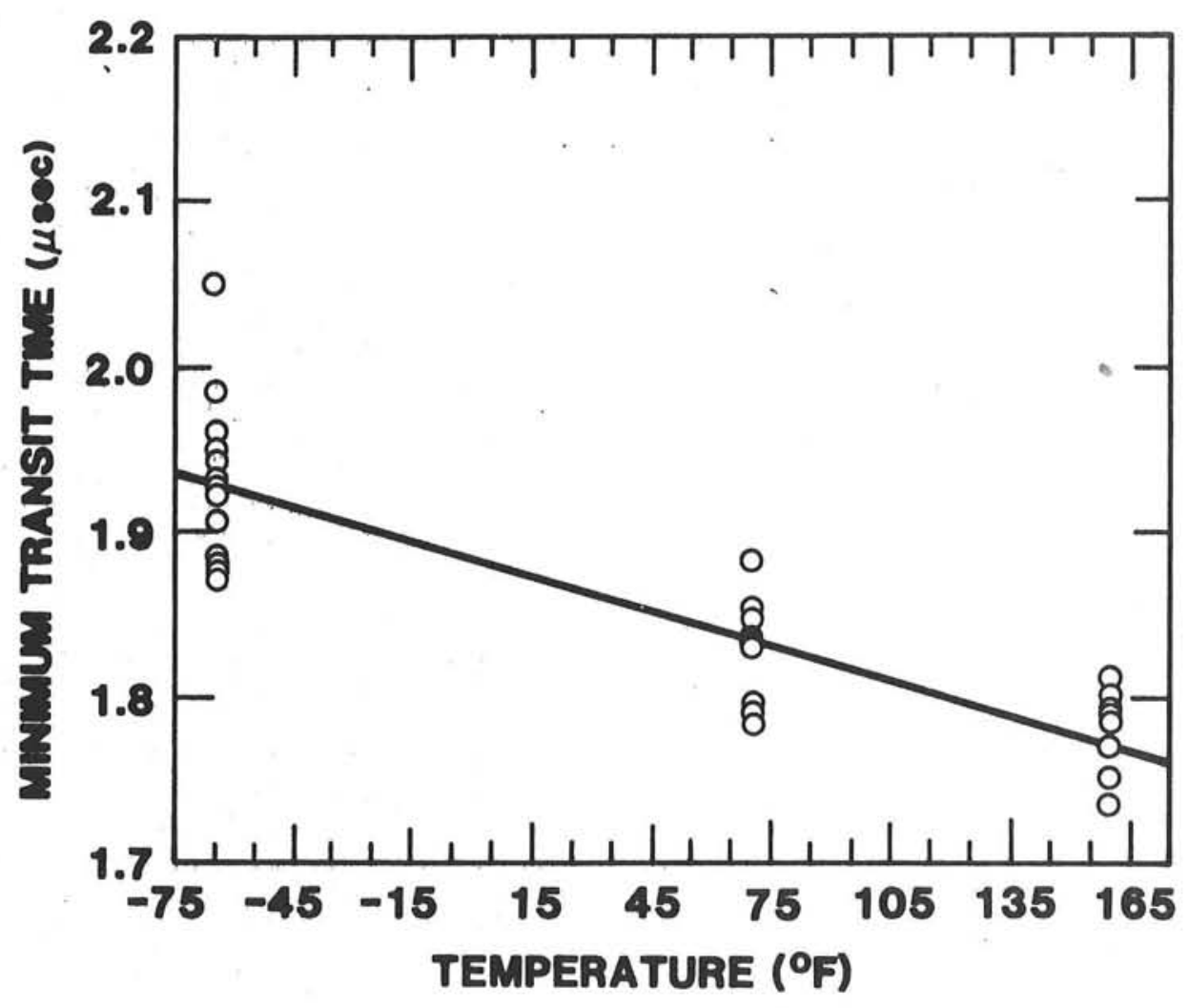

Figure 3. Minimum Transit Time vs. Temperature 
factor which probably controls the distance from bridgewire to the point of ignition is the input burst current which was constant in all measurements. The transit time measurements were conducted at an input current of $612 \pm 20$ amps; this is a factor of 2 , to 3 higher than the measured threshold burst currents. The time to ignition and/or the run-time to detonation are probably temperature dependent and will certainly affect transit time. Ignition should begin earlier and the deflagration rate should increase with increasing temperature since both are partially controlled by processes which are chemical in nature and both wil1 lead to lower transit times.

The threshold burst current for each temperature is plotted versus year of recrystallization in Figure 4. At significance levels of 0.01 to 0.1 , $\mathrm{I}_{\mathrm{bth}}$ at $-65,+70$, and $+160 \mathrm{oF}$ are inversely proportional to year of recrystallization. The Ibth for the screen tests are independent of year of recrystallization at significance levels of greater than 0.1 . No changes in the recrystallization process or testing procedures which could account for this behavior could be gleaned from existing records though many sma11 changes have been made over the past 15 years. Figure 5 shows Ibth versus year of recrystallization and temperature. It is observed that high firing temperatures in late lots of PETN lead to low threshold burst currents.

The minimum and maximum transit times versus year of recrystallization for each test temperature are shown in Figures 6-9. The transit times show no correlation with year of recrystallization. The +70 of tests show a slight decrease and 


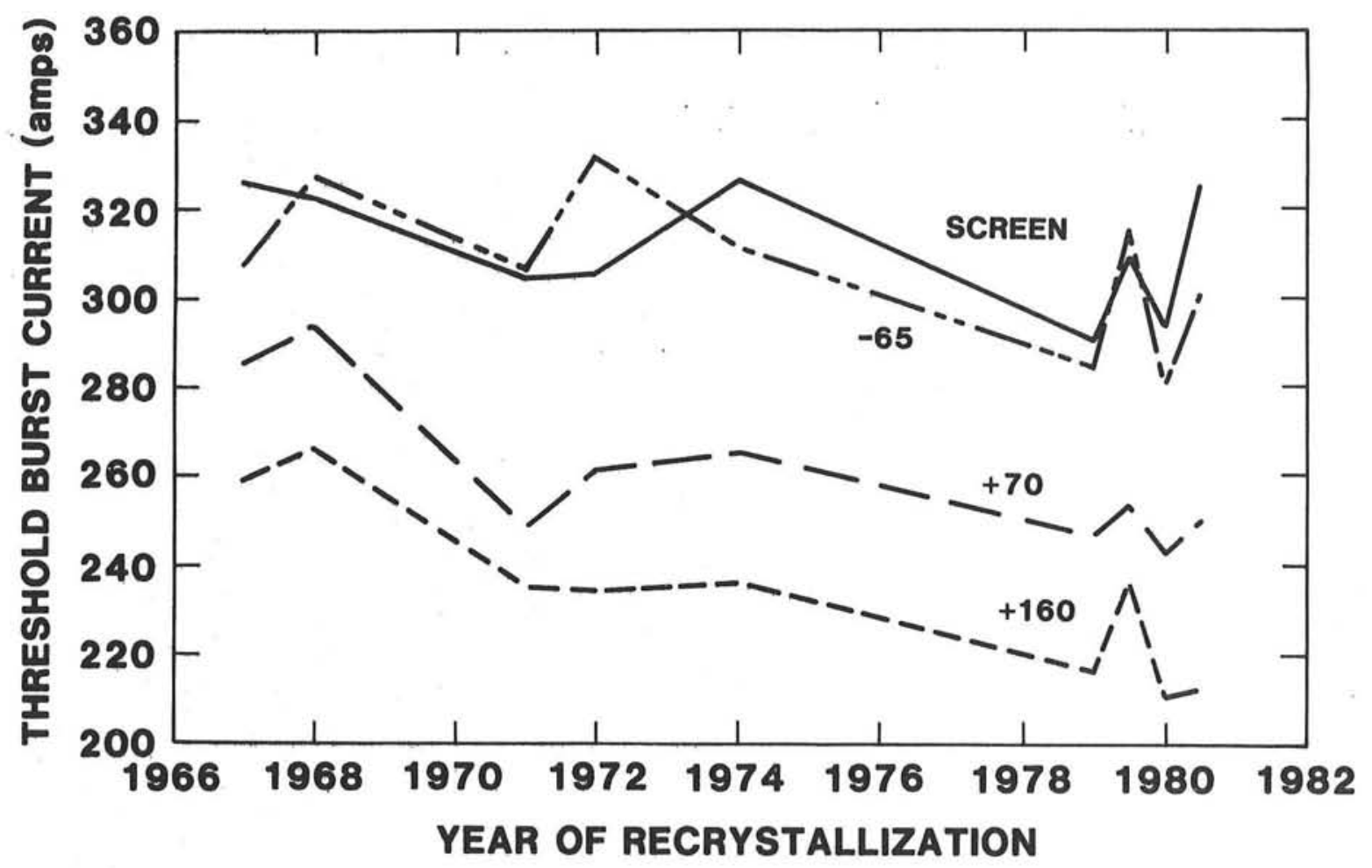

Figure 4. Threshold Burst Current vs. Year of Recrystallization 


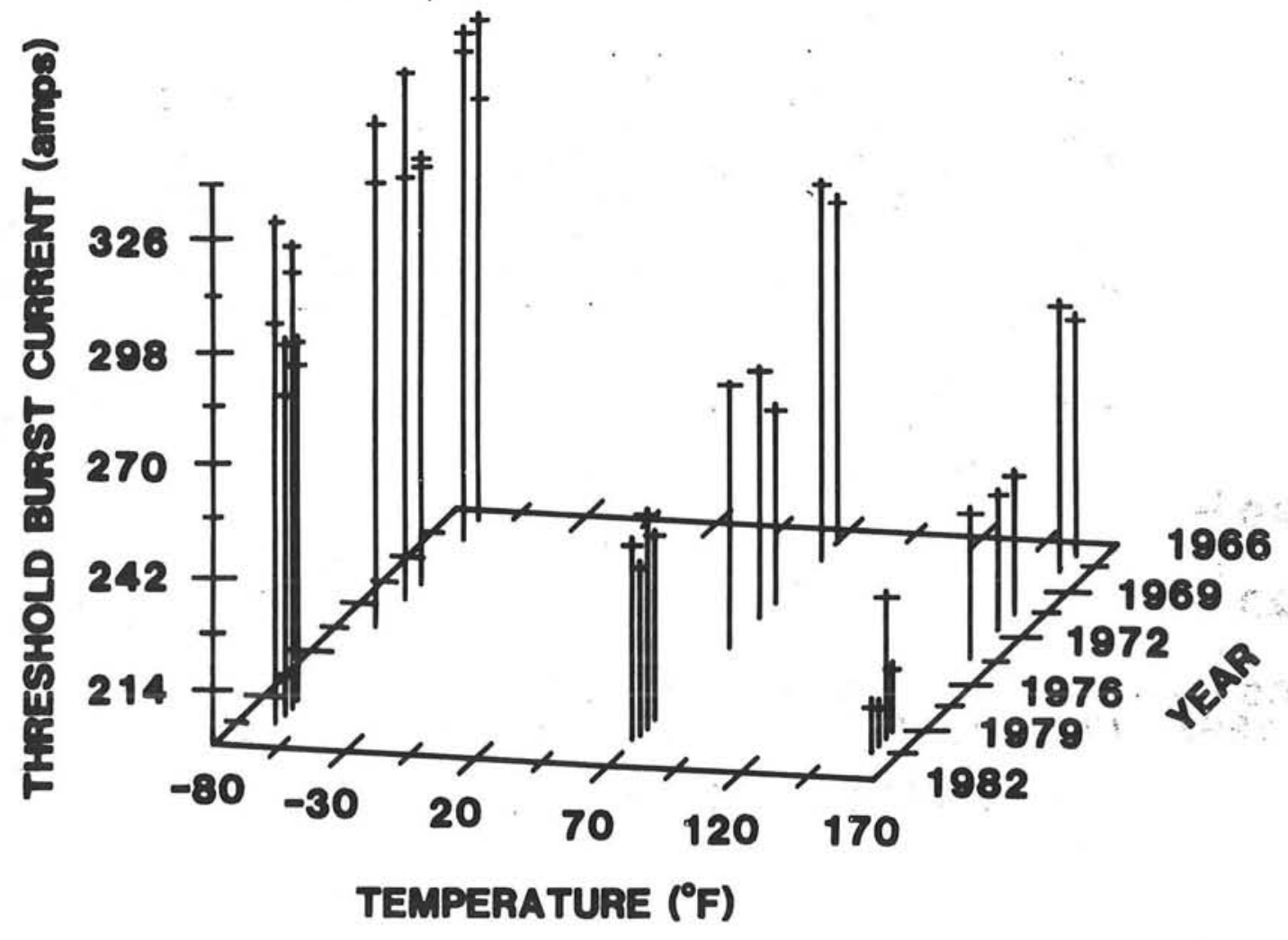

Figure 5. Threshold Burst Current vs. Temperature of Test and Year of Recrystallization 


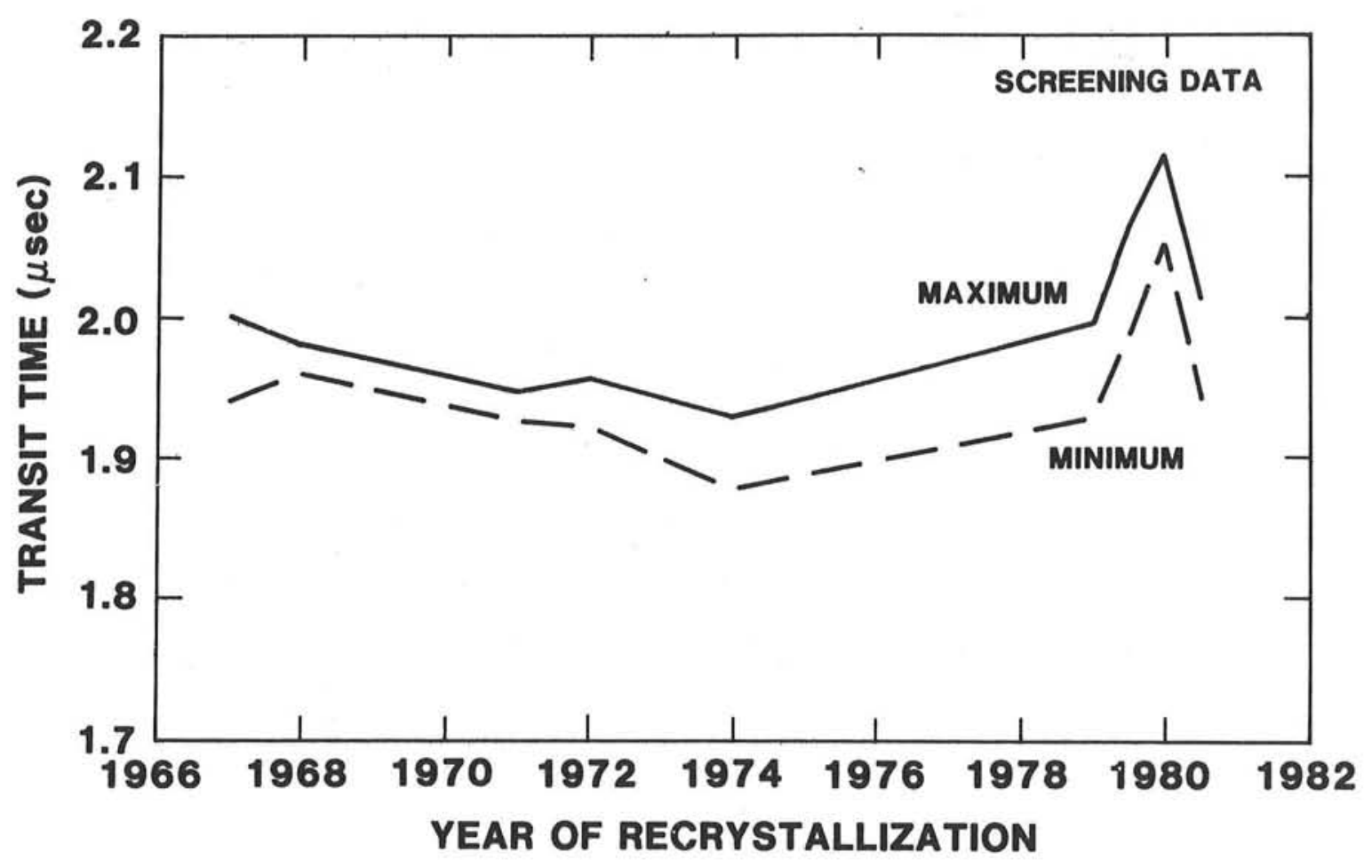

Figure 6. Transit Time for Screen Data vs. Year of Recrystallization 


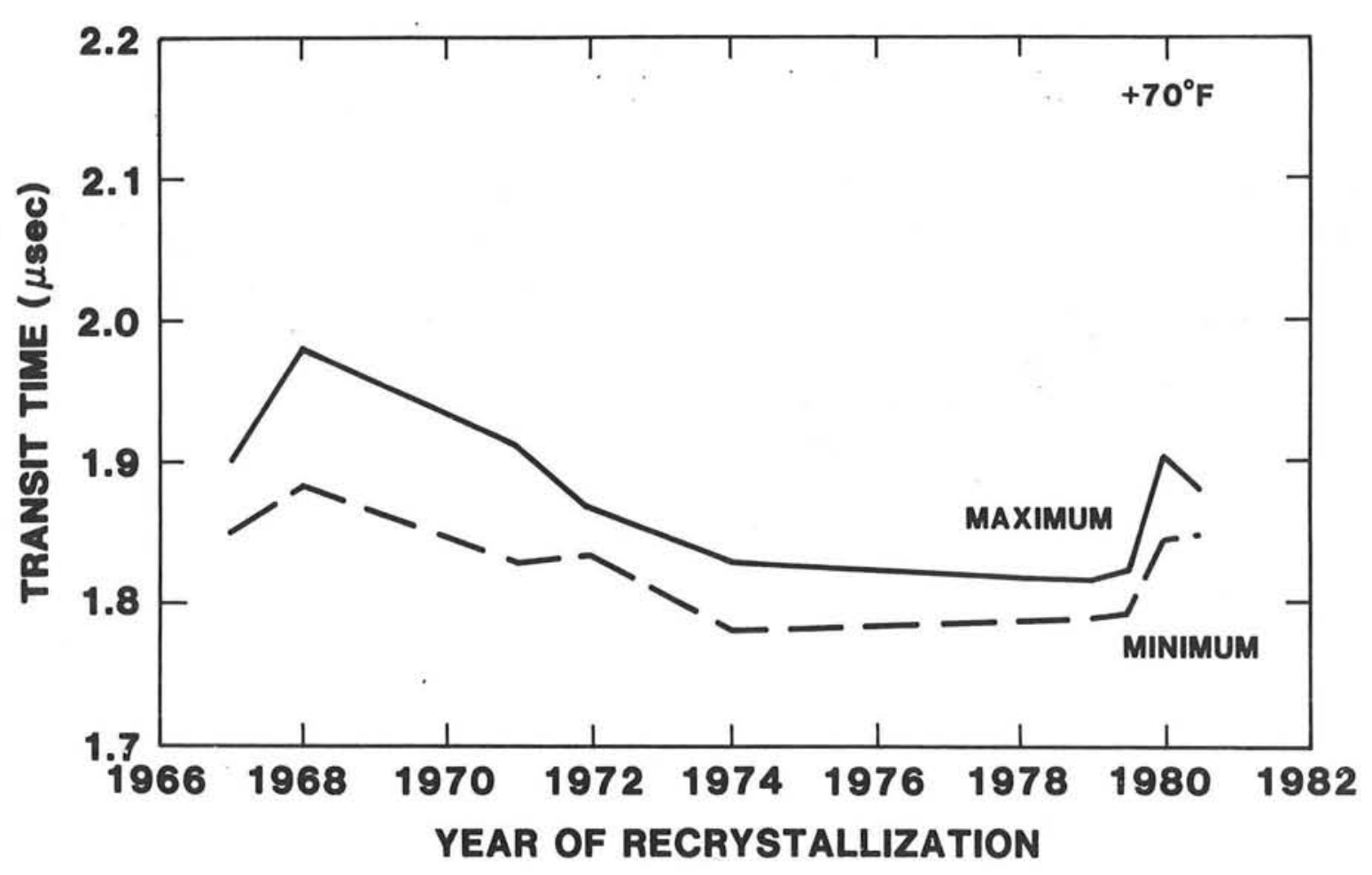

Figure 7. Transit Time at $+700 \mathrm{~F}$ vs. Year of Recrysta11ization 


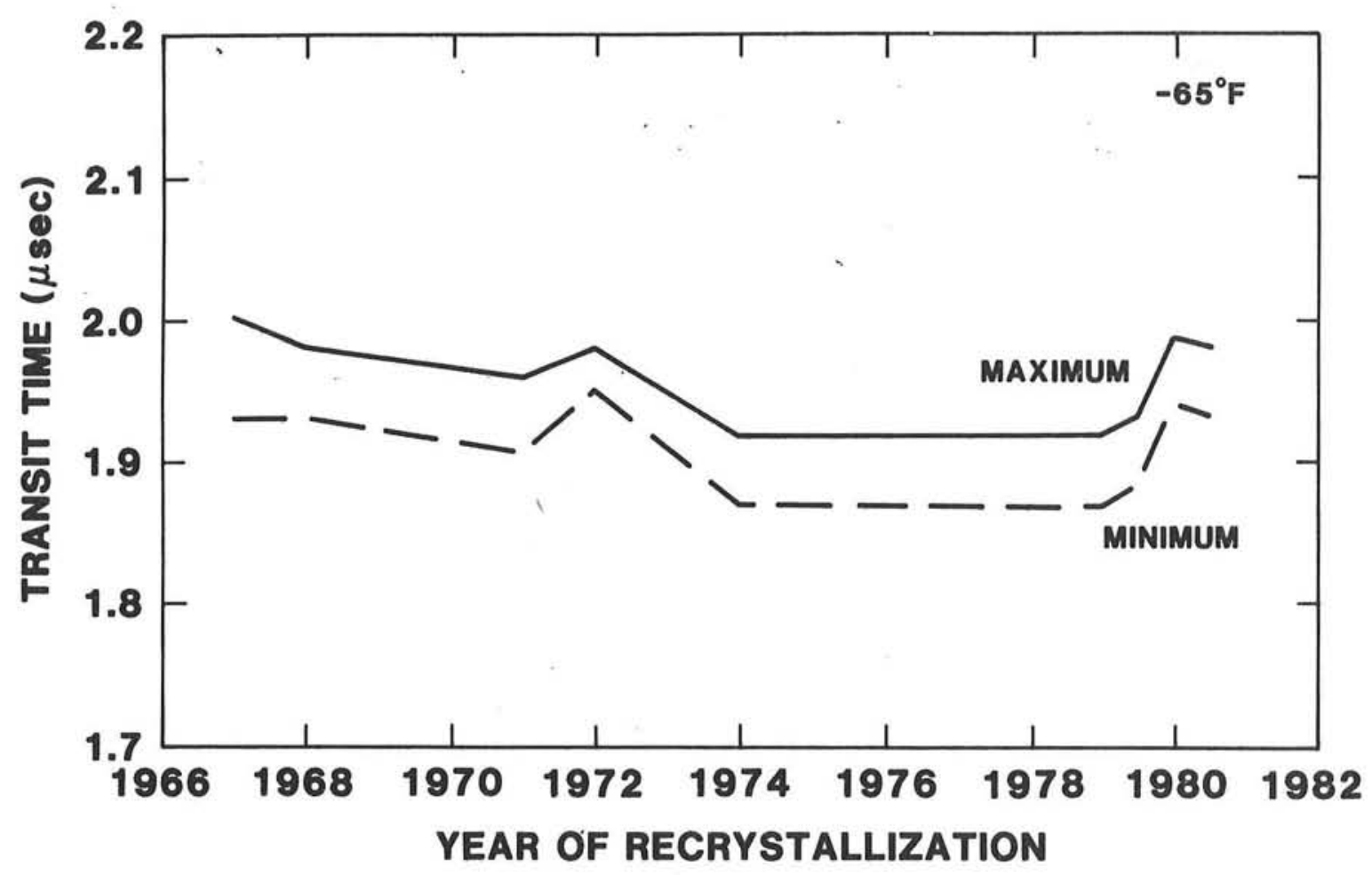

Figure 8. Transit Time at $-650 \mathrm{~F}$ vs. Year of Recrysta11ization 


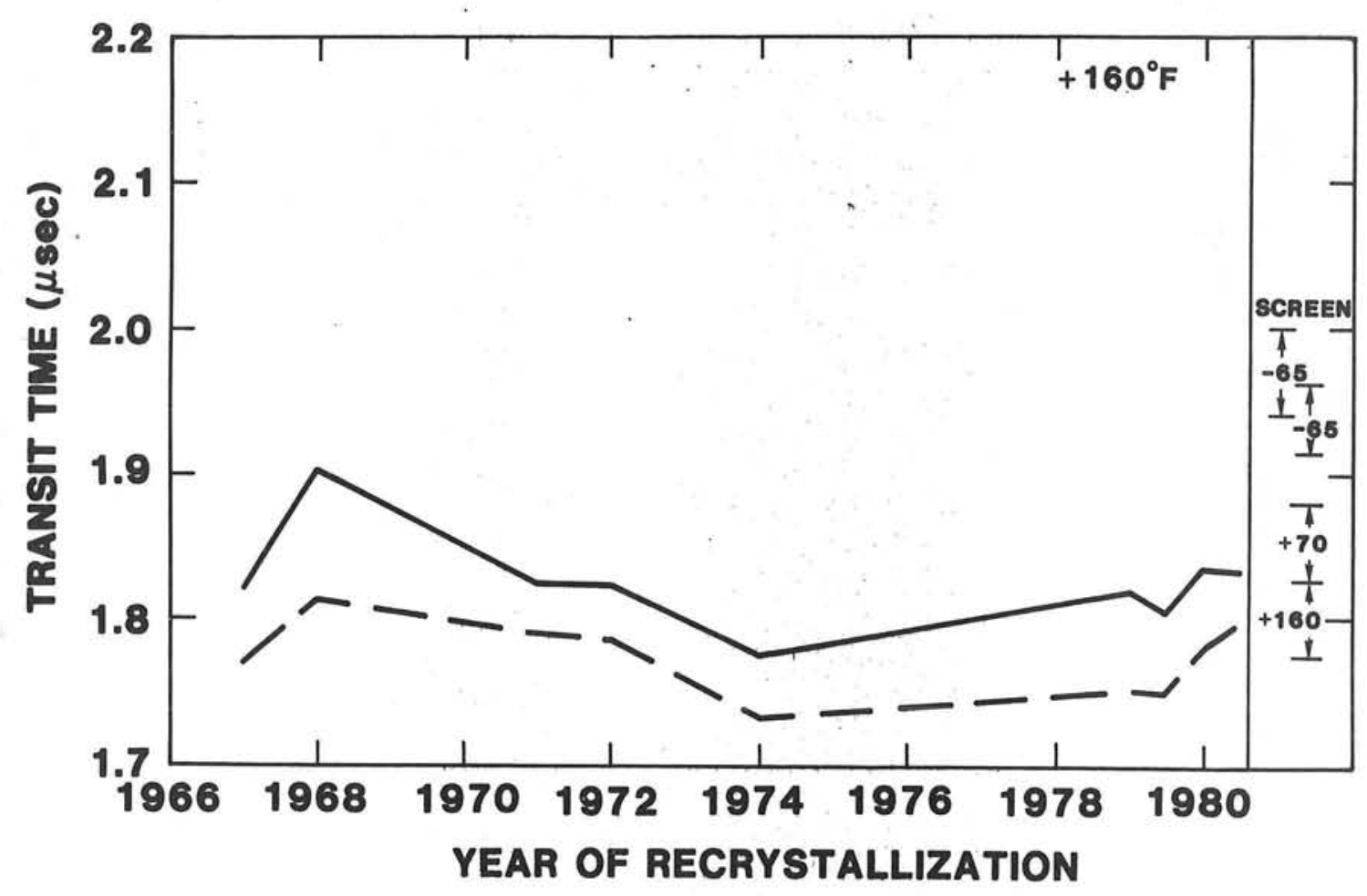

Figure 9 . Transit Time at $+1600 \mathrm{~F}$ vs. Year of Recrystallization 
the -65 of screen data show a small increase in transit time range for recent lots. Thus, for a given test temperature, the variation around a mean transit time appears to be constant and very reproducible from lot to lot. In fact, as shown in Figure 10 , where the actual ranges of transit times $\left[t_{e}(\max )-t_{e}(\min )\right]$ are plotted as a function of year of crystallization, the maximum variation in range of transit times over the 15 years of production is less than $70 \mathrm{nsec}$.

It was pointed out earlier that the maximum and minimum transit times vary inversely with temperature. This is clearly depicted to the right of Figure 9 where the mean minimum and maximum transit times for the nine lots are shown at the three test temperatures. The bands of absolute transit time show little overlap with bands at other test temperatures.

No correlation was found between the standard deviation of burst currents, $\sigma\left(\mathrm{I}_{\mathrm{bth}}\right)$, and environmental conditions nor was a correlation found between thermal cycling or mechanical shock and any other performance measurement.

\section{Linear Correlations Among Performance Tests}

Simple linear correlations of the different PETN performance tests were made to see their relationships to each other. The correlations are shown in Table 3. At a significance of 0.001 , it was found that $I_{b t h}$ was correlated with $t_{e}(\max )$ and $t_{e}(\min )$; when $I_{b t h}$ was high, so were the transit times as shown in Figures 11 and 12 . The best correlation was found when $t_{e}(\max )$ and $t_{e}(\min )$ were compared. Figure 13 shows that when the $t_{e}(\max )$ is high, so is $t_{e}(\min )$. 


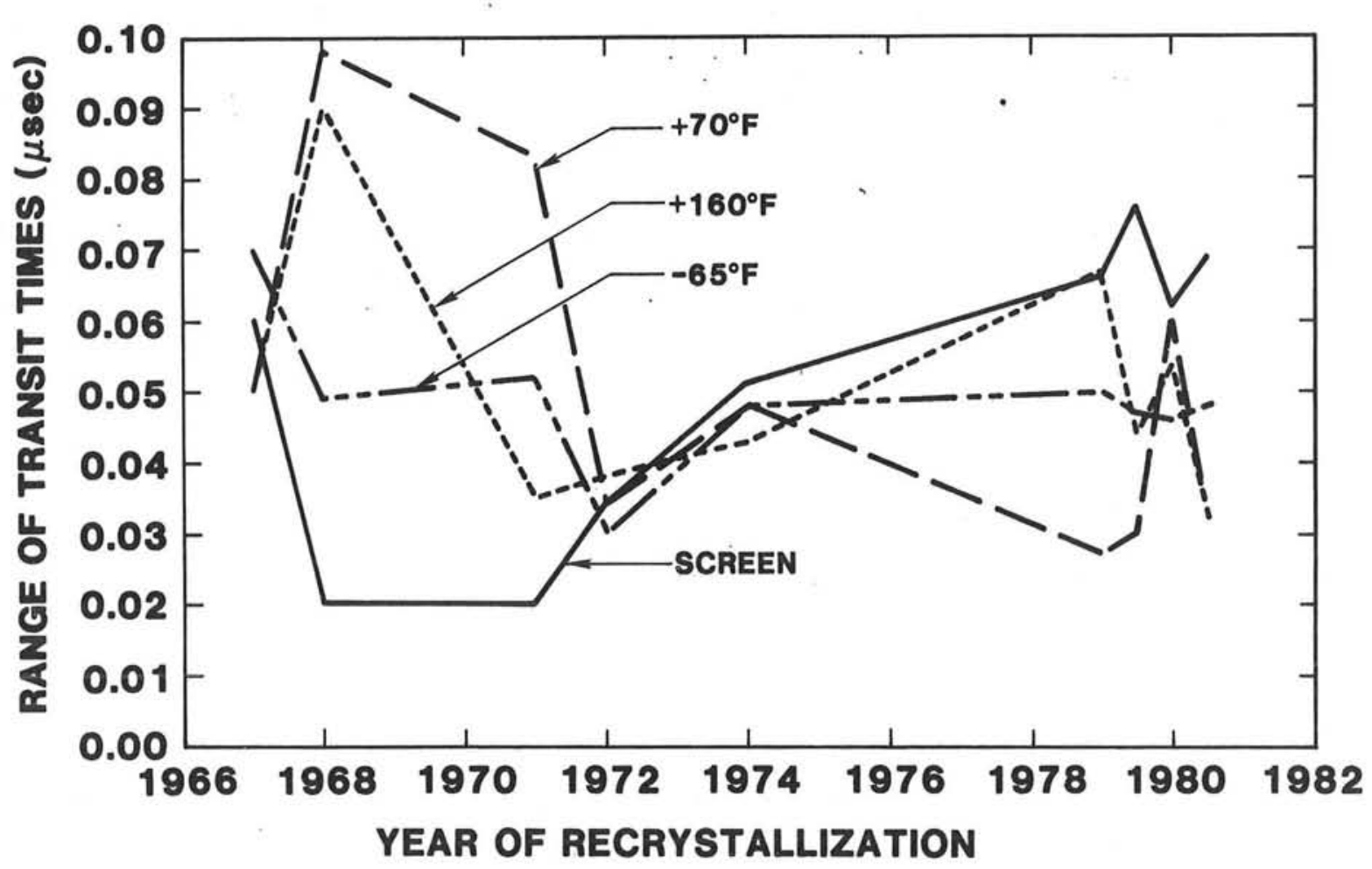

Figure 10. Range of Transit Times vs. Year of Recrystallization 


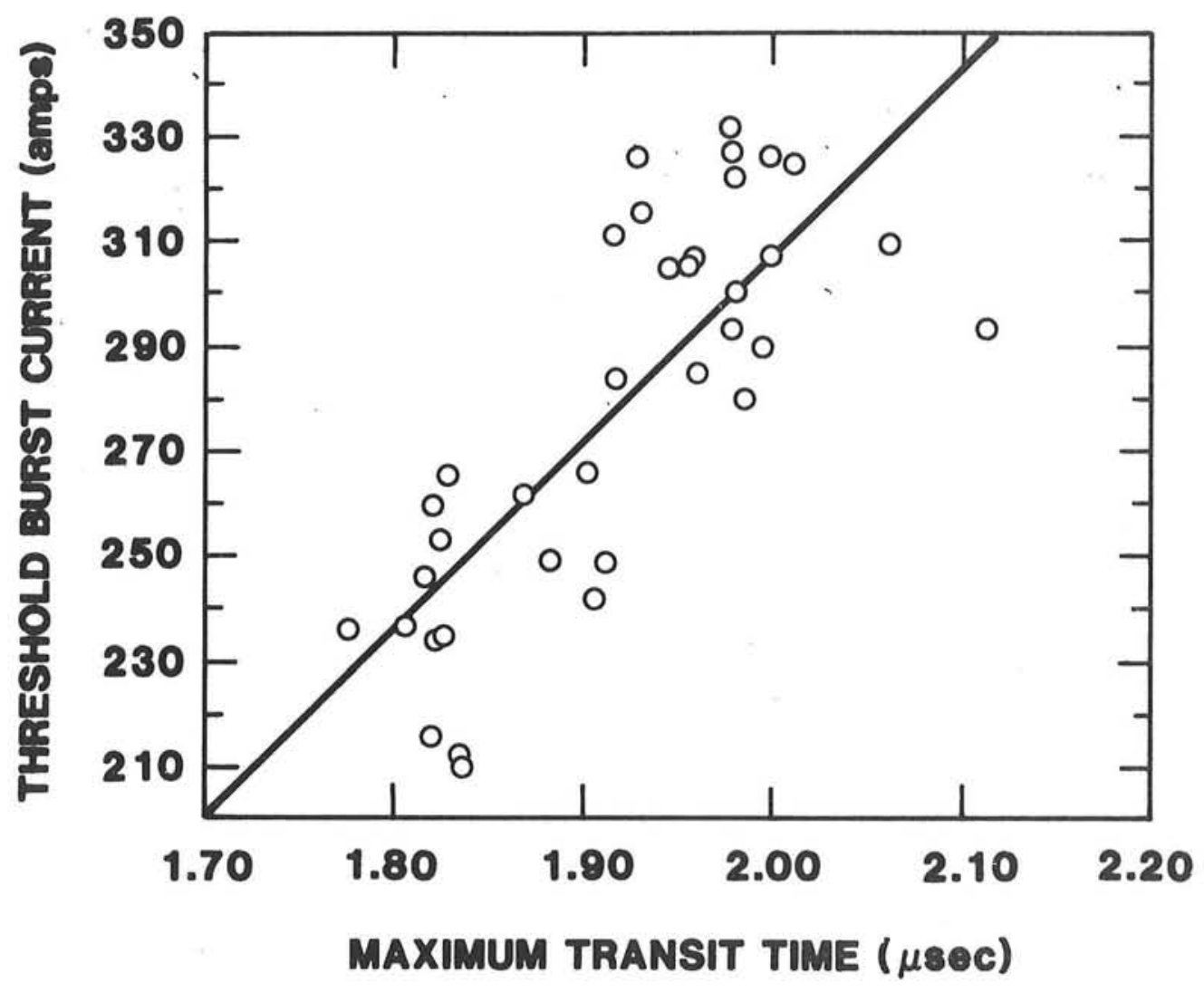

Figure 11. Threshold Burst Current vs. Maximum Transit Time 


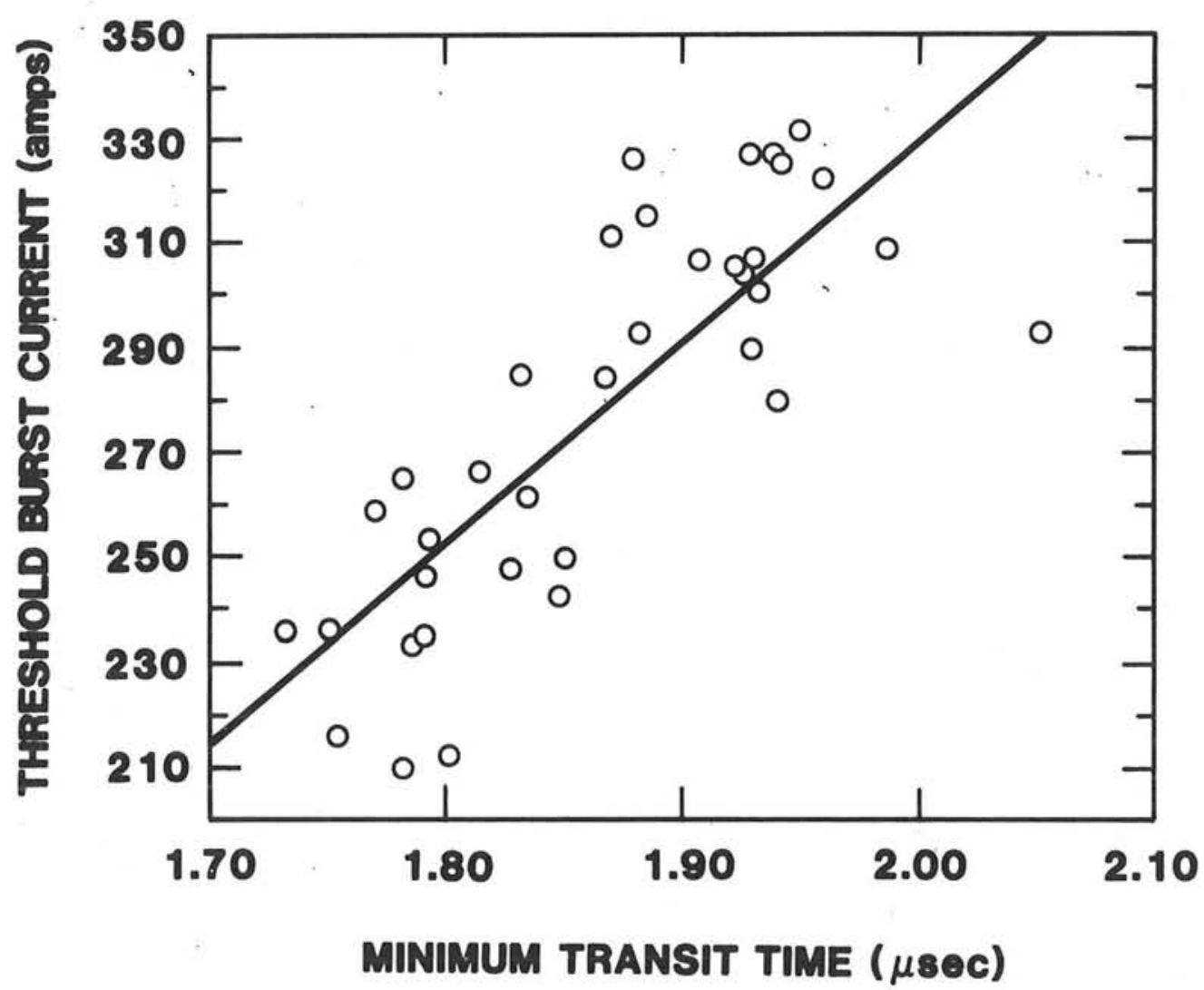

Figure 12. Threshold Burst Current vs. Minimum Transit Time 


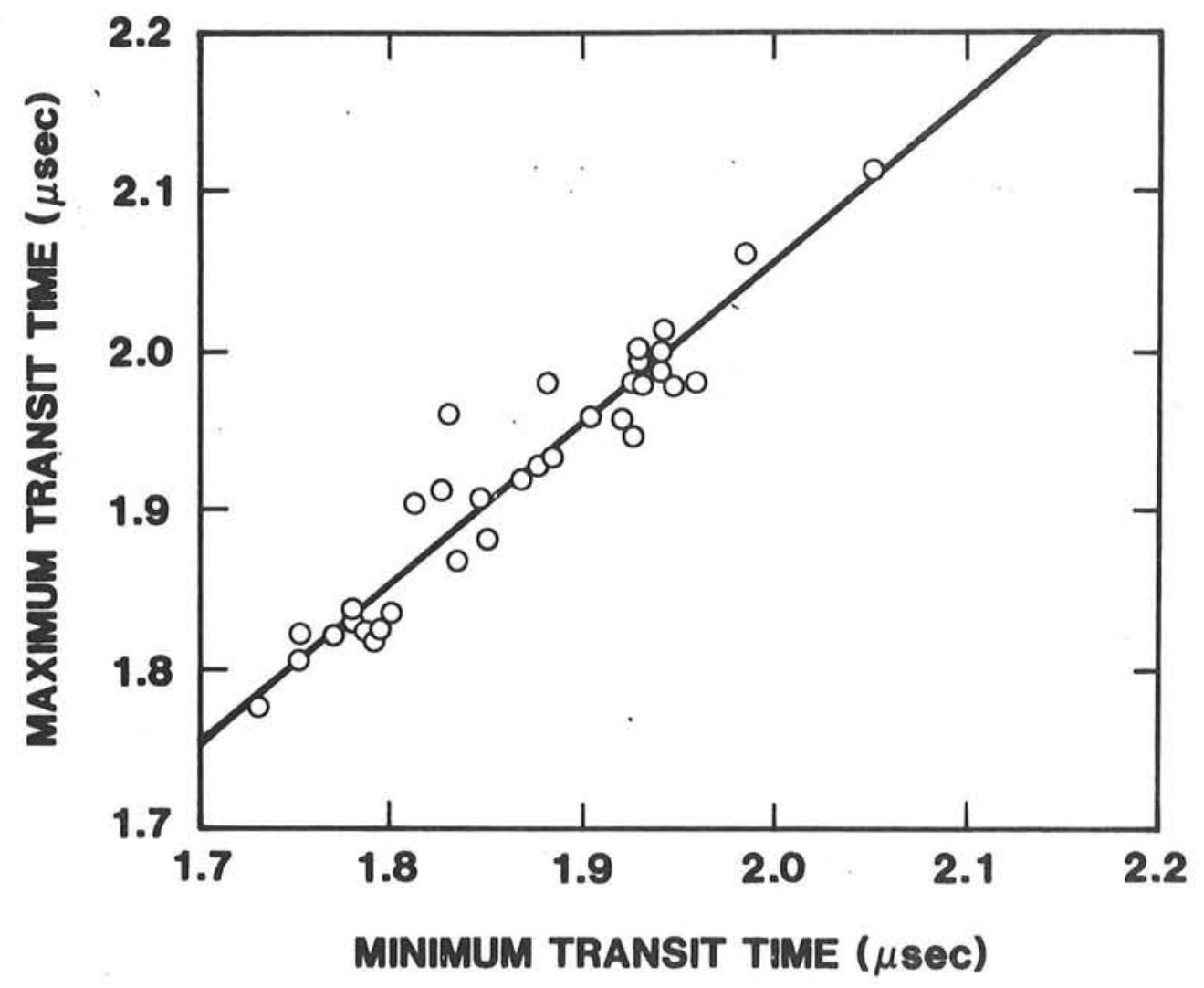

Figure 13. Maximum vs. Minimum Transit Time 
The standard deviation of the threshold burst current, $\sigma\left(\mathrm{I}_{\mathrm{bth}}\right)$, is weakly correlated with the range of transit times (Figure 14).

Table 3

Simple Linear Correlation Coefficients

Involving RR5K PETN Performance

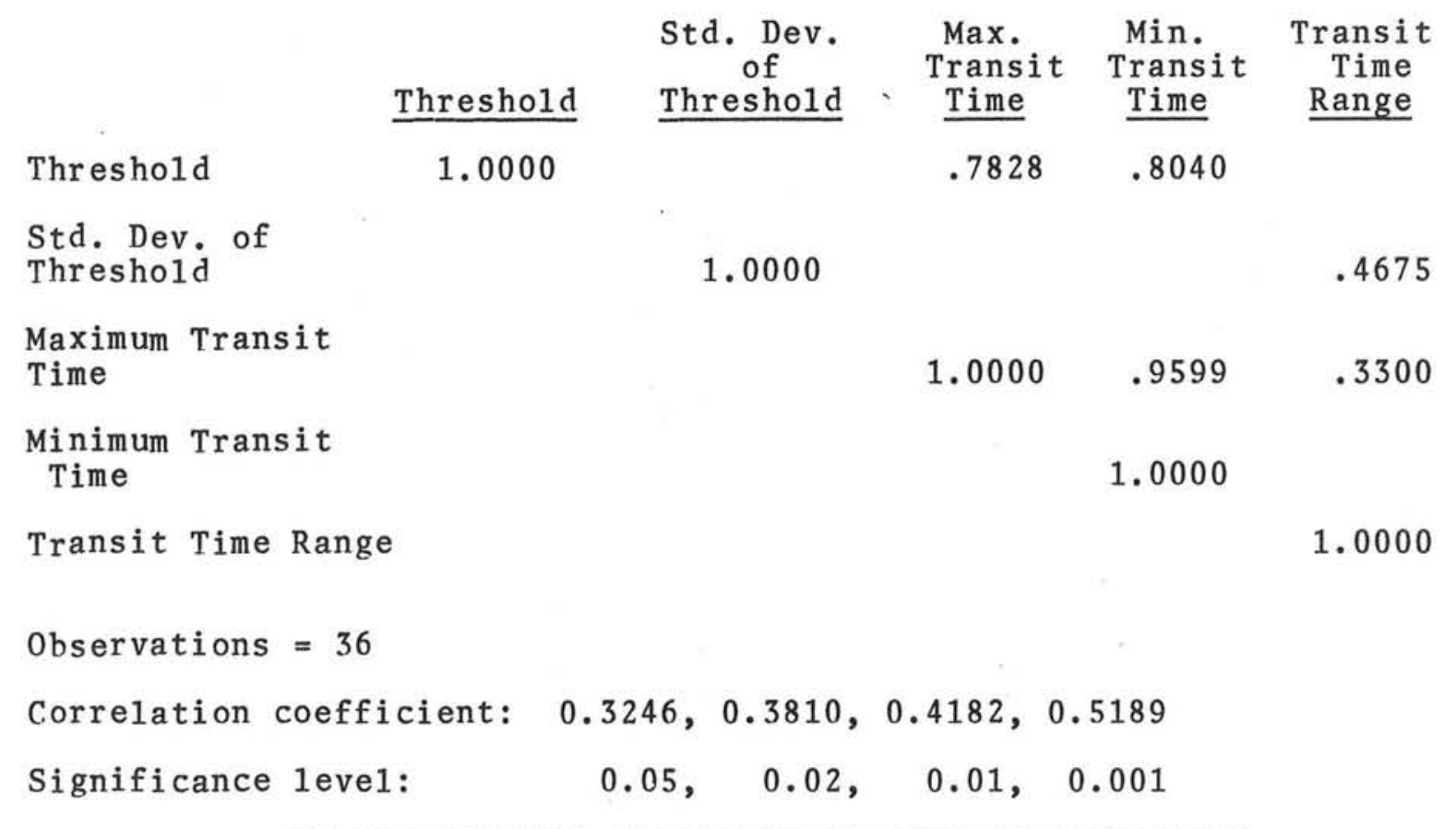

D. Prediction Models

When a new lot of PETN is produced a decision must be made as to whether it will perform as required. Aside from subjecting the lot to the entire test fire matrix, which is expensive, the only other parameter currently measured is the FSSS surface area. As mentioned, lots having passed FSSS specification $(5000 \pm 300$ $\mathrm{cm}^{2} / \mathrm{g}$ ) have failed to test fire as specified.

To determine which particle characteristics can reliably predict firing behavior the results from linear regression among 


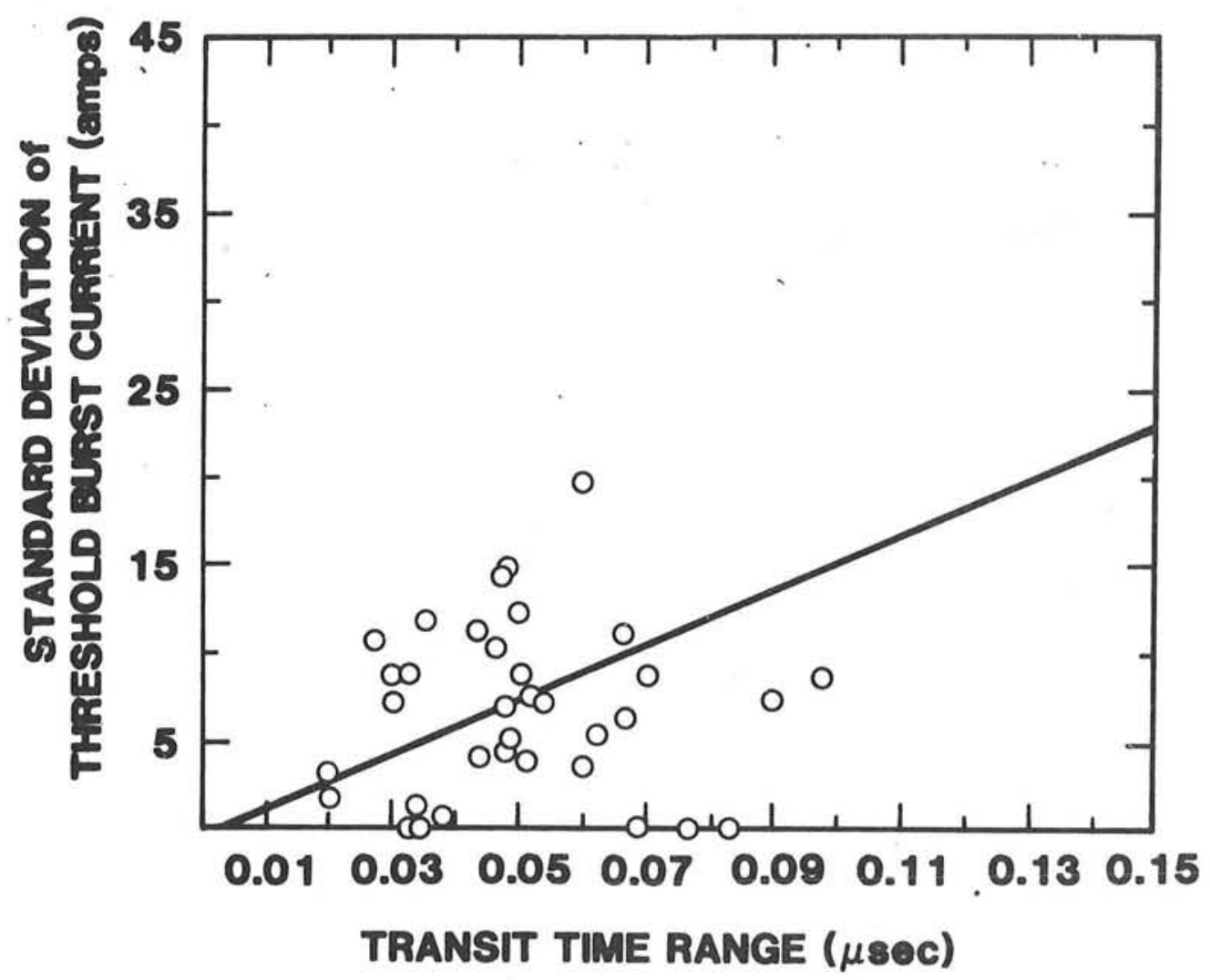

Figure 14. Standard Deviation of Threshold vs. Transit Time Range 
the independent variables in Table 1 and the test fire results (dependent variables) from Table 2 were used to construct prediction models. These models are summarized in Table 4.

One such model, the threshold burst current at +160 of will be discussed as an example. Examining Table 4, the mean $\mathrm{I}_{\text {bth }}(+160)$ for the nine lots is $233.78 \pm 19.50$ amps. The formula for the prediction of $\mathrm{I}_{\mathrm{bth}}(+160)$ is:

$$
\begin{aligned}
\mathrm{I}_{\mathrm{bth}}(+160) \text { predicted }=352.21- & 12.93(\text { LWR-Qrt25-F) } \\
+ & 36.86(\text { CSA-Mo Skew-W }) \\
& -56.20 \text { (LWR-PctEst-F) amps. }
\end{aligned}
$$

The actual variables (column four) have been substituted here for $x_{1}, x_{2}$, and $x_{3}$ in the table. The mean value and standard deviation of each variable in the model are also included in the table. For instance, the mean value of the 25 th quartile of the length/width ratio frequency distribution, LWR-Qrt25-F, for the nine PETN lots is $1.68 \pm 0.79$.

The partial correlation coefficient is a measure of the strength of the correlation and its sign tells whether the correlation is positive or negative. The multiple correlation coefficient squared tells what percentage of the data is explained by a given variable. In the present case, $52.7 \%$ of the variation of $\mathrm{I}_{\mathrm{bth}}(+160)$ is explained by inclusion of the first variable, LWR-Qrt25-F. If two variables are included, this percentage increases to $79.5 \%$. The standard error of estimate is also included in Table 4. Thus, the error in predicting $I_{b t h}(+160)$ using a11 three variables is \pm 9.05 amps. 
Table 4. Prediction Models for RR5K PETN

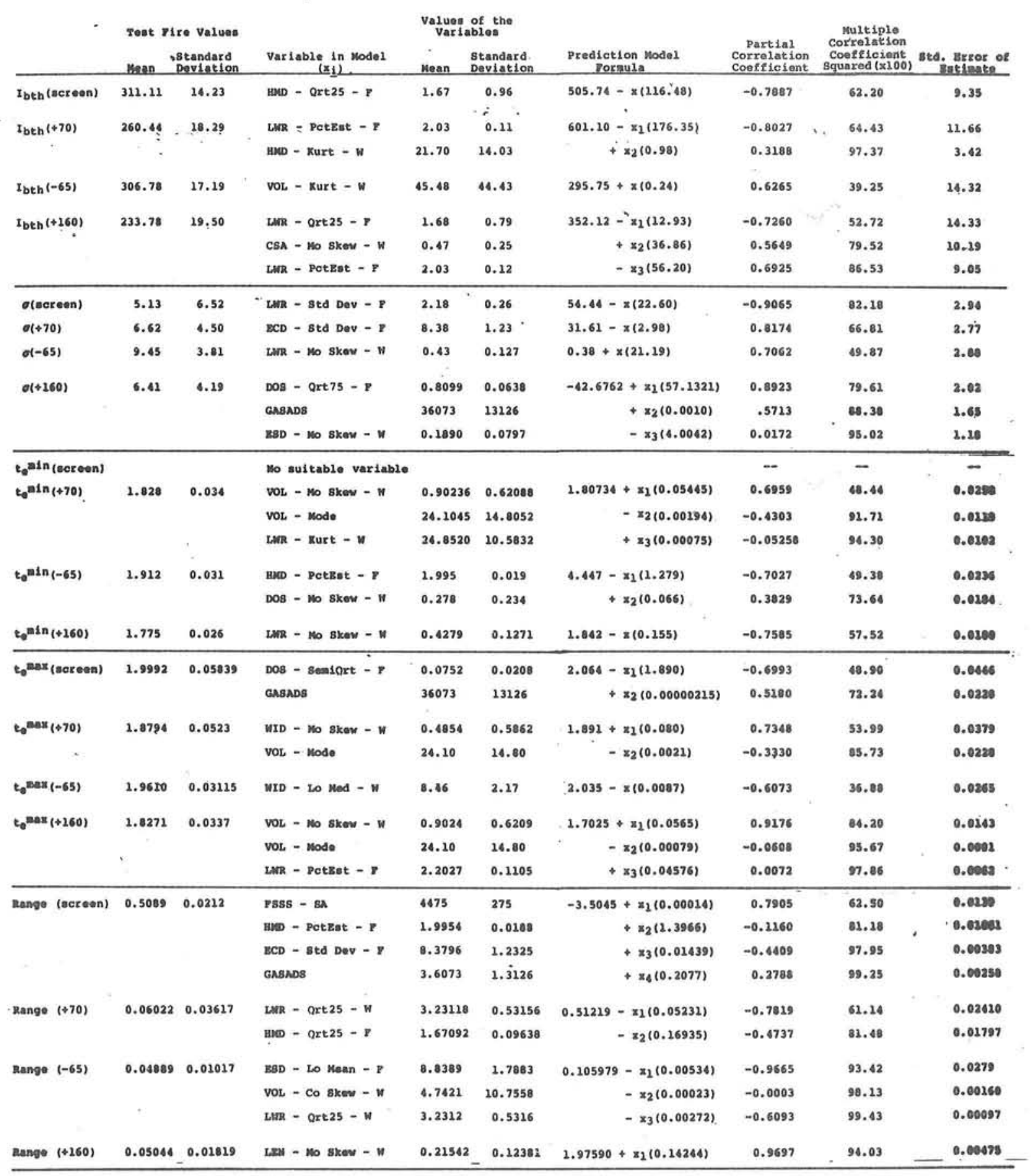


the "chubby" particles, the threshold burst current will decrease.

The third variable, LWR-PctEst-F, the percentile estimate of the frequency distribution of length/width ratios is a measure of the central tendency of this shape distribution. The percentile estimate is defined as

$$
\text { PctEst }=\frac{\text { Qrt75 }+ \text { Qrt25 }}{\text { Qrt50 }}
$$

and the burst current is inversely dependent on this variable.

To increase the percentile estimate, we can increase Qrt25 and/or Qrt75 or decrease Qrt50. We previous1y observed from the first variable that Qrt25 needs to be increased. Using the variables from other models in Table 4 (not discussed) Qrt75 also needs to be increased. This gives a wider range of shapes with more needle-1ike or elongated particles. Analysis of this particular variable shows how all variables must be considered in order to develop a consistent picture.

Analysis of all the prediction models revealed trends which are summarized below.

Threshold burst current. A wide distribution of sizes and shapes with elongated or long needle-like particles having low crosssectional areas leads to low $\mathrm{I}_{\mathrm{bth}}$. Standard deviation of threshold burst current. A wide symmetric distribution of shapes and a wide distribution of sizes skewed right with more needle-like particles and less reentrants gives low $\sigma\left(I_{b t h}\right)$. 
The prediction models provide an inexpensive, reliable method for prequalification of new lots of material. The FSSS, BET, and Zeiss characterization, including data reduction, can a11 be determined in less than two man-days. This is considerably less expensive than completing the entire test fire matrix.

The prediction models are only valid over the independent variable range from which they were determined. For instance, if a new lot of material has a LWR-Qrt25-F value which is out of the range of those from the original nine lots, the prediction model and $I_{b t h}(+160)$ predicted may not be reliable.

Aside from their obvious applications to pre-screening, the prediction models are also valuable in determining which particle characteristics influence performance. Again the three variables in the $I_{b t h}(+160)$ model will be used as an example. Usually, lower values of threshold hurst current are considered desirable. As the first variable (LWR-Qrt25-F) increases, Ibth $(+160)$ decreases. The length/width ratio is a shape parameter (see Appendix IV). As Qrt25 increases, the distribution becomes more elongated or needle-1ike and less cubic or spherical.

The second variable is the momental skewness of the crosssectional area by weight, CSA-MoSkew-W. As the momental skewness decreases, so does $I_{b t h}(+160)$. The momental skewness is a measure of the deviation of a distribution compared to a normal distribution and in this case, the positive value indicates the distribution is skewed right, toward large cross-sectional areas. By decreasing the particles with large cross-sectional areas, 
Maximum transit time. A wide distribution of shapes with large average size and the larger size needle-like (no wide particles) leads to 1 ow $t_{e}(\max )$.

Minimum transit time. A wide distribution of shapes and large size needles leads to low $t_{e}(\min )$.

Transit time range. A tightly grouped shape and size distribution, with low FSSS surface areas and the largest sizes needlelike, leads to low transit time ranges. (Note: there were some inconsistencies in the variables from the transit time range mode1s.)

These findings were remarkably self-consistent with the exception of some conflicting behavior in the transit time range models. An interesting and unexpected observation is that long needlelike particles lead to short transit times. It has generally been observed that small particle sizes give the fastest transit times [6]. One possible explanation for the present results is that after pressing into detonators, the long needle-like PETN crystals are crushed to give small, well-packed particles. The PETN is pressed to a density of $0.88 \mathrm{Mg} / \mathrm{m}^{3}$, roughly one-half the crystal density of PETN. Such pressing will crush needlelike particles but not large diameter particles [7].

IV. Summary and Conclusions

RR5K PETN is used in several Department 2510 exploding bridgewire detonators. It has been in production for fifteen years over which time period nine lots have been made. The existing test fire and particle parameter data base is complete yet small enough to be statistically manageable thus providing an ideal system to study the effects 
of environmental conditions and particle characteristics on explosive performance.

To test which environmental conditions influence performance, the test fire results were correlated with temperature, date of recrystallization, and previous environmental conditioning. The threshold burst current and transit times are inversely proportional to the temperature of test fire. A weak inverse correlation also exists between threshold burst current and the date of recrystallization but none was found between thermal cycling, mechanical shock, or mechanical vibration and explosive behavior.

Particle characteristics were measured by several methods to determine which of these parameters influence explosive behavior. The measurements were made on a large number of particles to obtain adequate statistics. After subjecting the results to statistical analysis, prediction models were obtained and are presented in the text. One of these has been described in detail as an example. These models may be useful in pre-screening future lots of RR5K PETN. Moreover, the variables used in the prediction models add insight into which particle parameters influence threshold burst current and transit times. Parameters which have a positive influence on threshold burst current are also found to have a positive effect on transit times. Interesting1y, wide shape and size distributions with the largest sizes being needle-like lead to 1 ow burst currents and short transit times. We speculate that these powder distributions ultimately cause uniform packing of the explosive bed after the particles are crushed by compaction during loading into detonators. 


\section{References}

1. H. E. Anderson, "STAT/LIB", SAND74-0225, Sandia Nationa1 Laboratories, Albuquerque, NM, October 1974.

2. The surface-volume diameter is defined as the diameter of a sphere having the same external surface area to volume ratio as the particle b्eing measured (Ref. 8, pg. 75, 335).

3. The shape factors for Zeiss Analysis are rectangular, disc, sphere, prisms or cones, ellipsoids, and agglomerates.

4. Biomedica1 Computer Programs (BMDP), Factor Analysis (P4M), P-series, University of California Press, Berkeley, California (1979) pg. 656.

5. Biomedical Computer Programs (BMDP), Stepwise Regression (P2R), P-series, University of California Press, Berkeley, California (1979) pg. 399.

6. J. E. Kennedy and J. G. Harlan, 2513, private communication.

7. A. A. Duncan, unpublished.

8. T. Allen, Particle Size Measurement, Chapman and Ha11, London, 1975 . 


\section{APPENDIX I}

Photomicrographs of RR5K PETN

Production Lots 


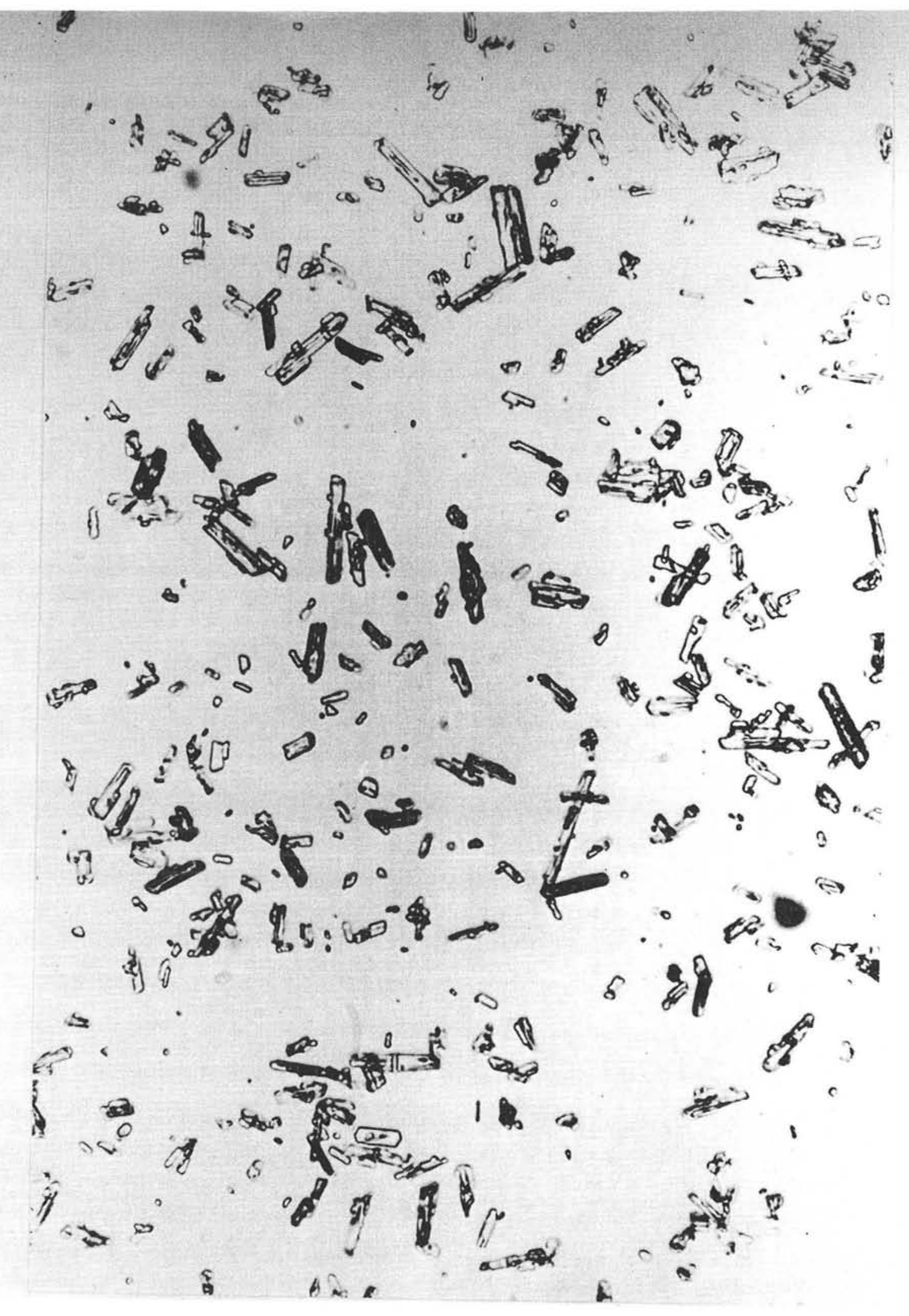

Figure I-1 RR5K PETN Lot 1201 


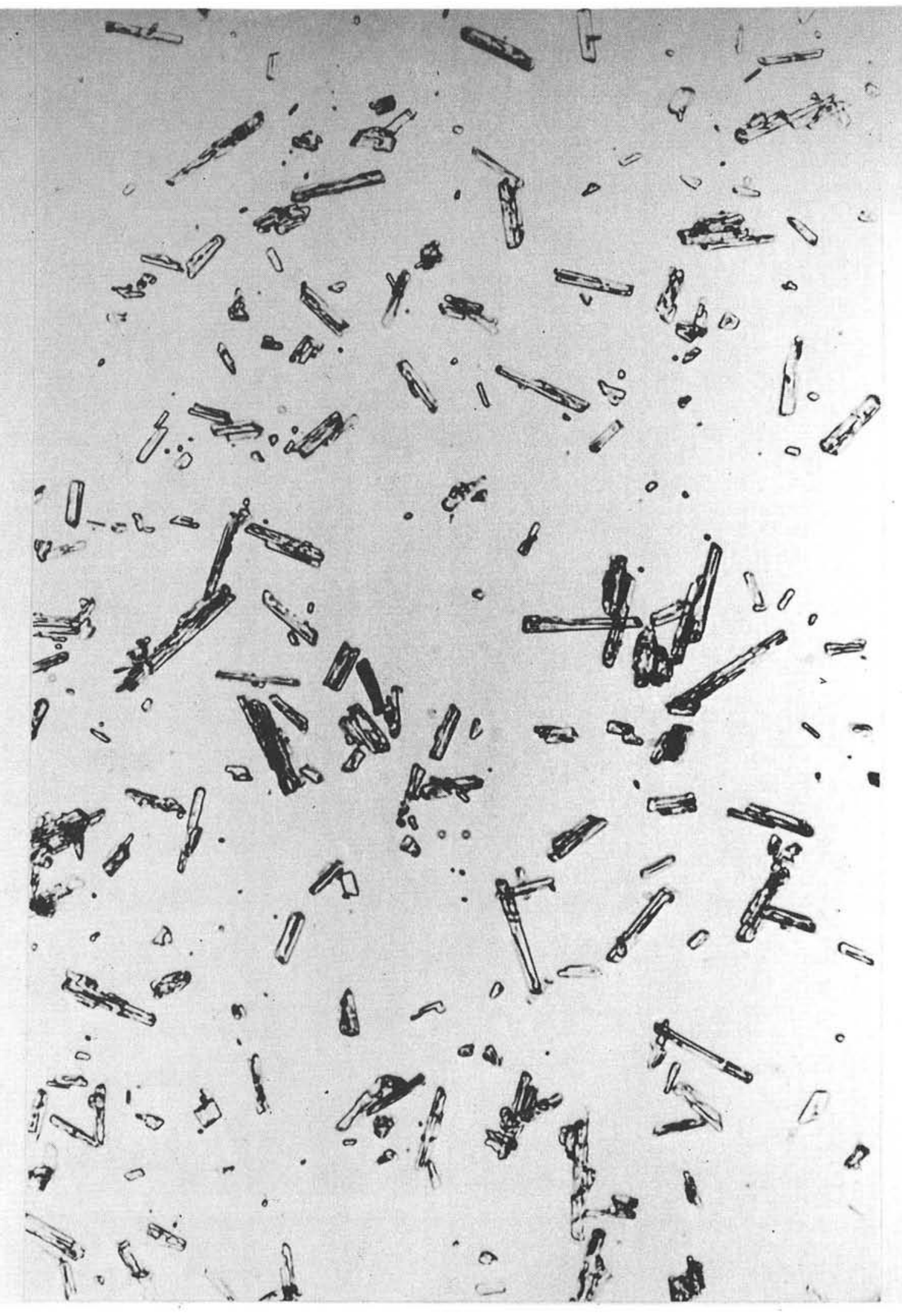

Figure I-2 RR5K PETN Lot 1159 


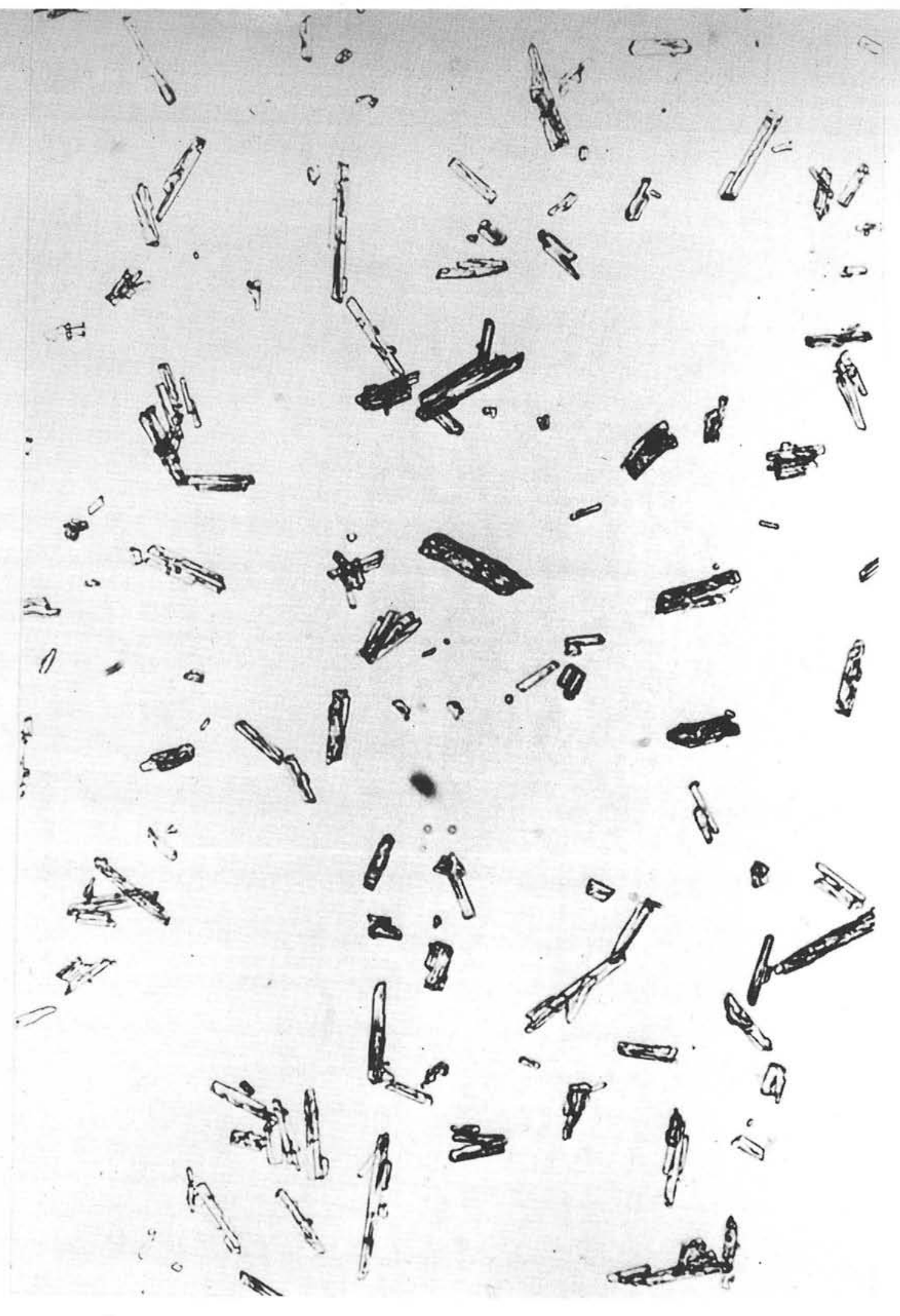

Figure I-3 RR5K PETN Lot 1204 


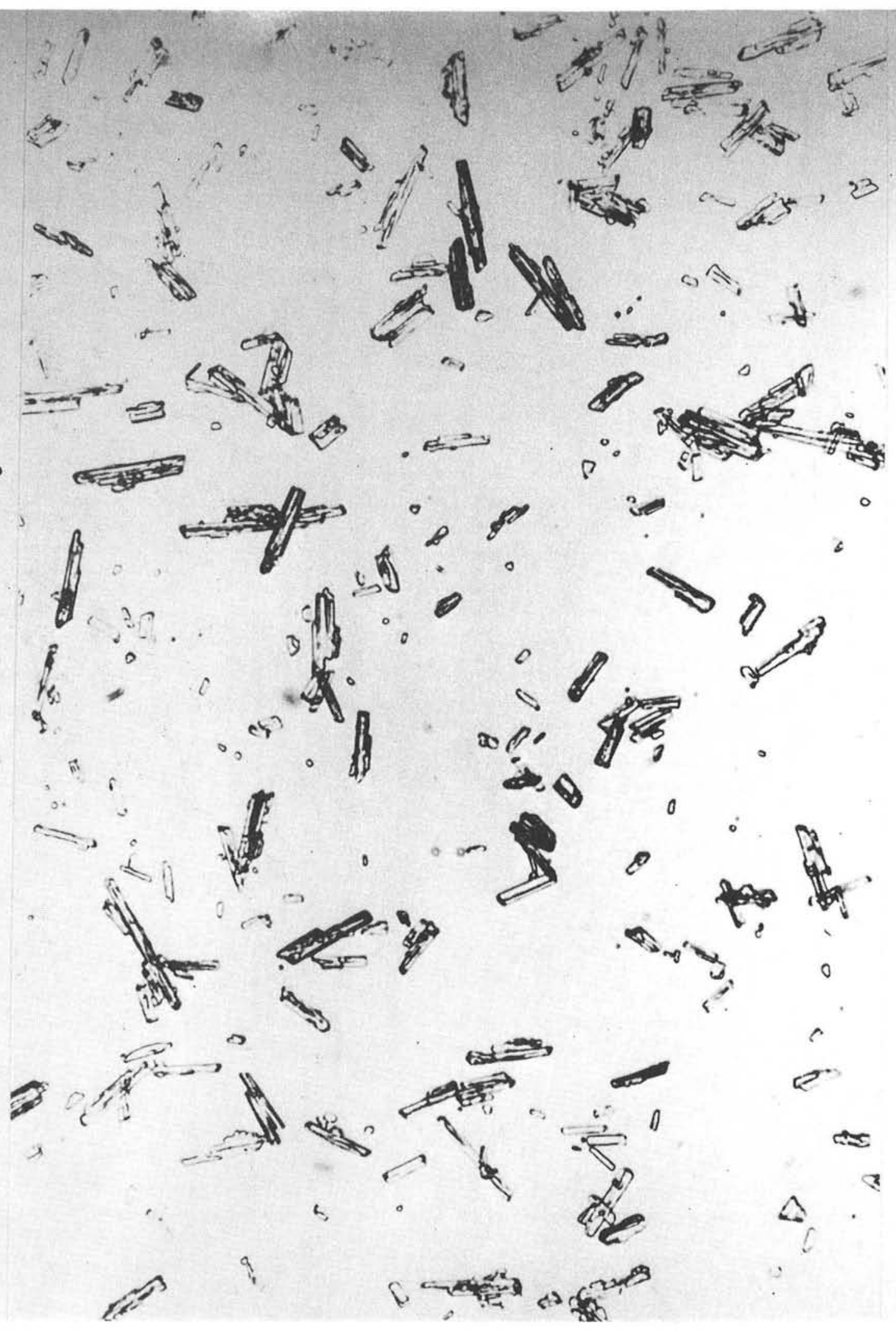

Figure I-4 RR5K PETN Lot 1206 


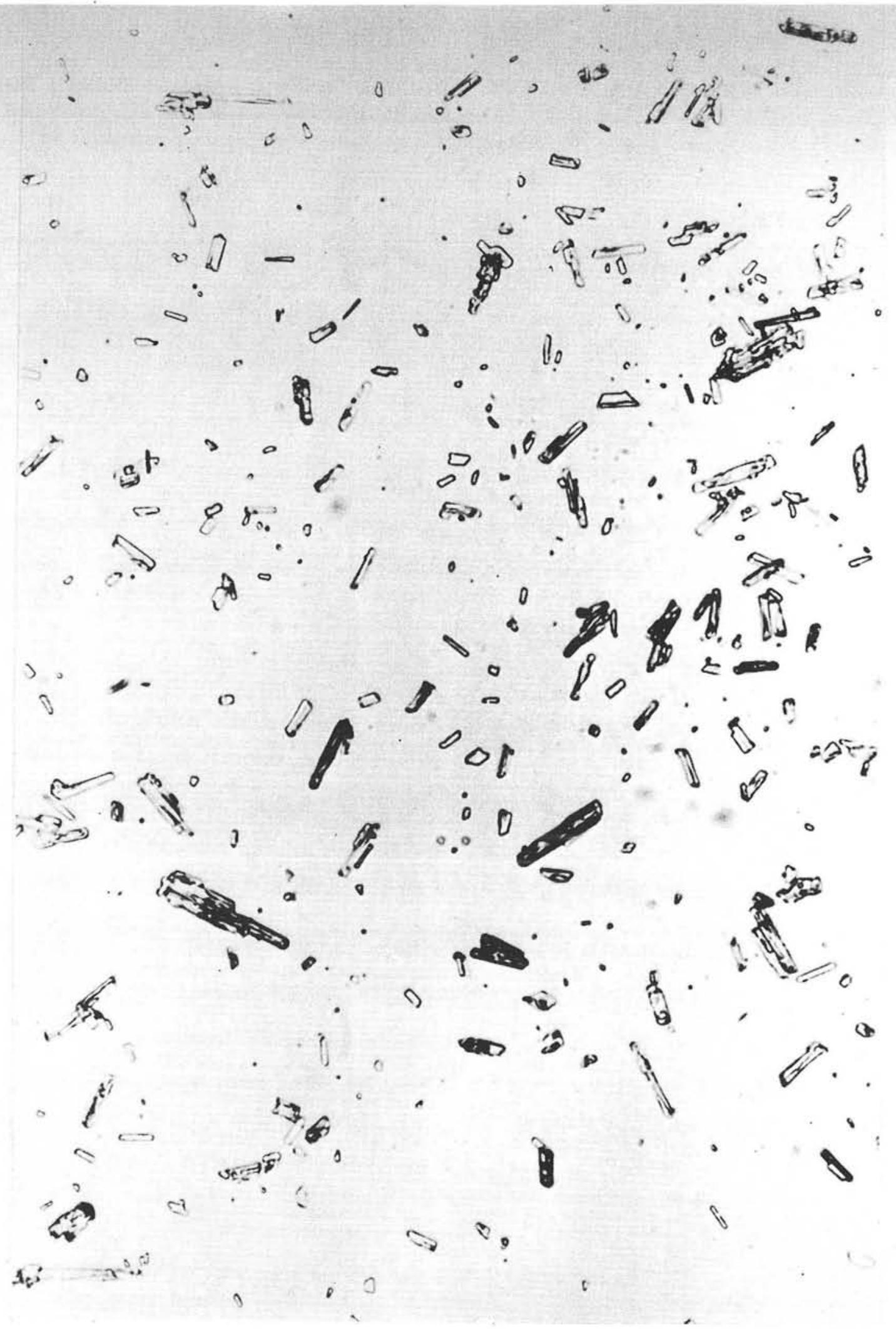

Figure I-5 RR5K PETN Lot 1258 


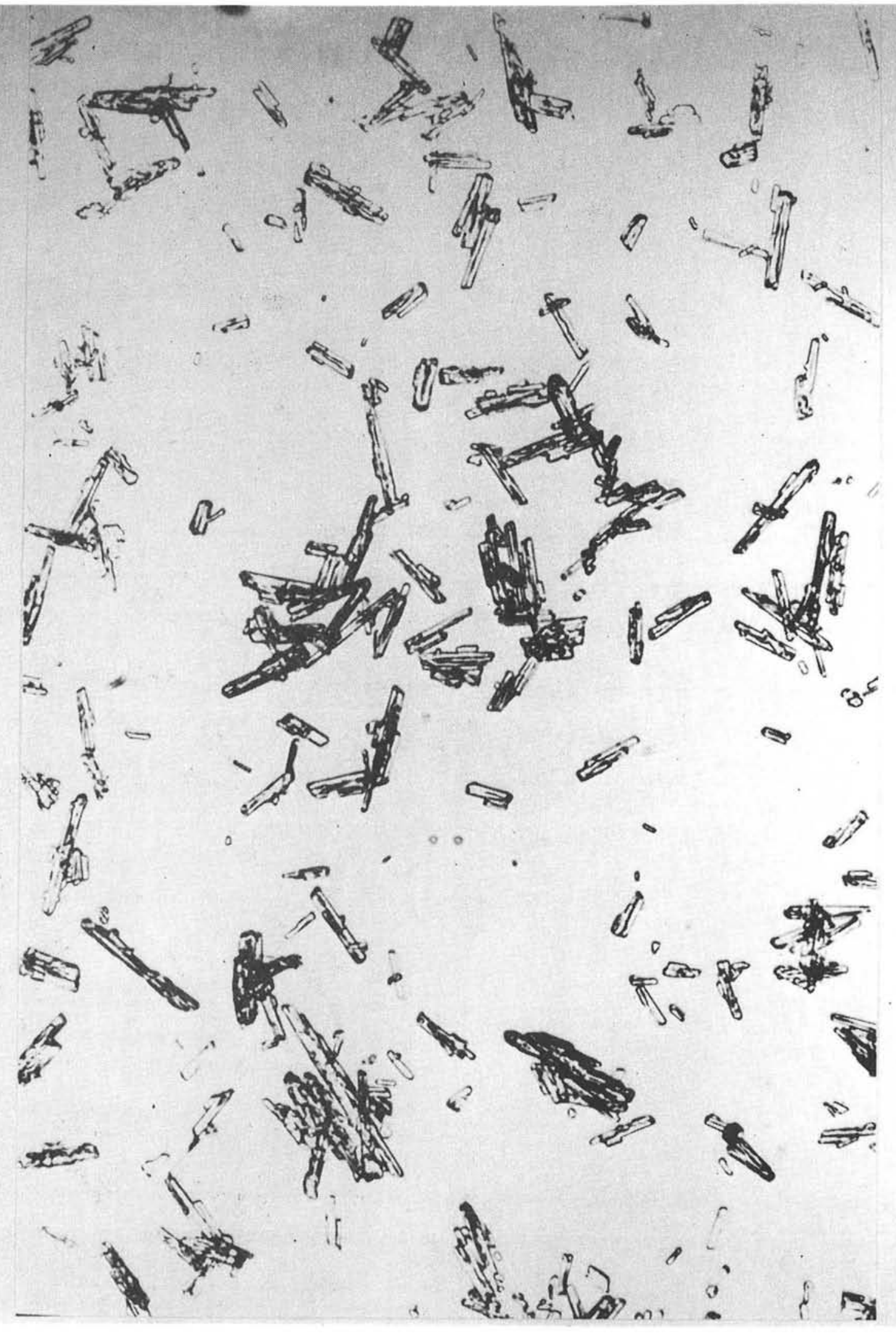

Figure I-6 RR5K PETN Lot 1375 


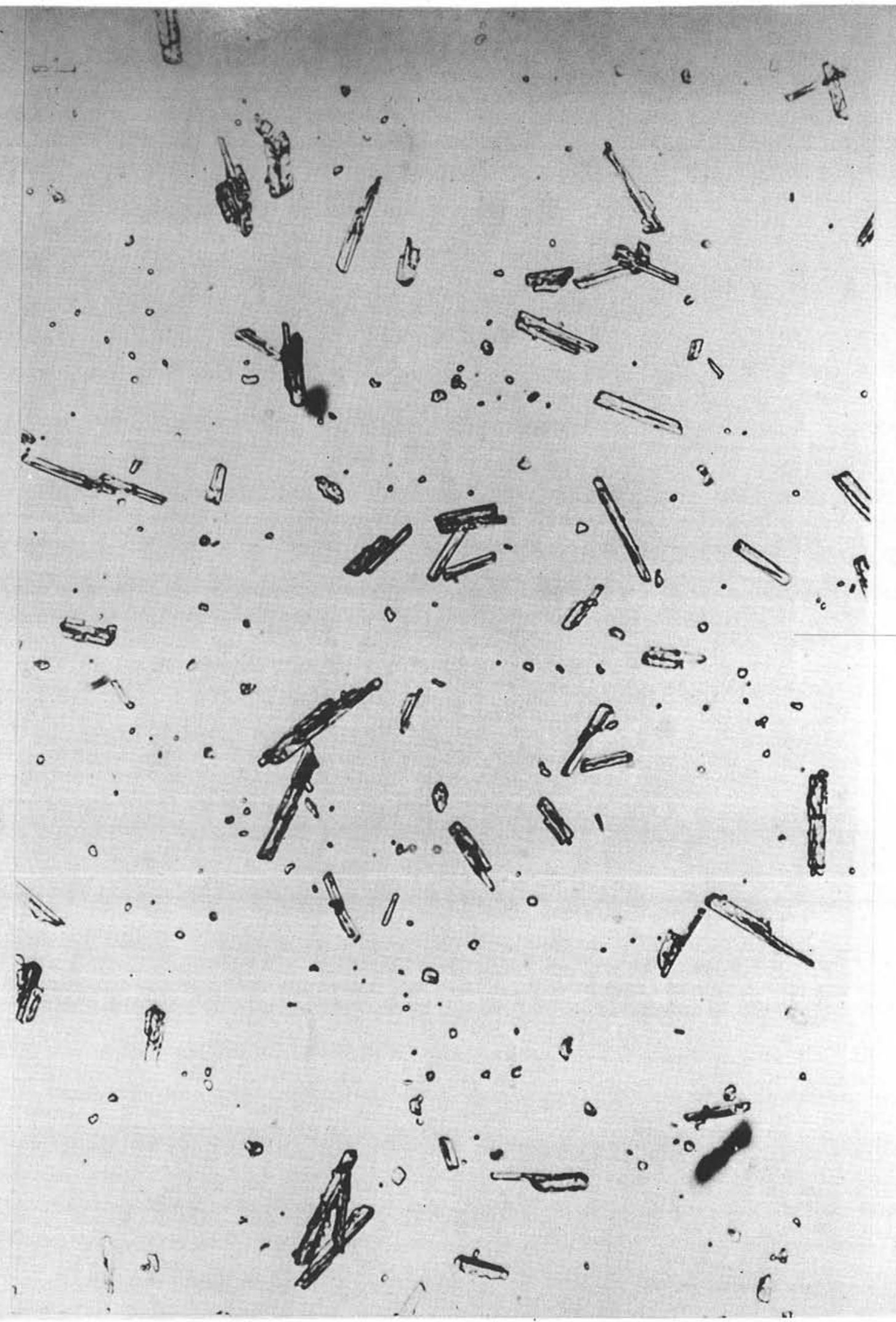

Figure I-7 RR5K PETN Lot 1376 


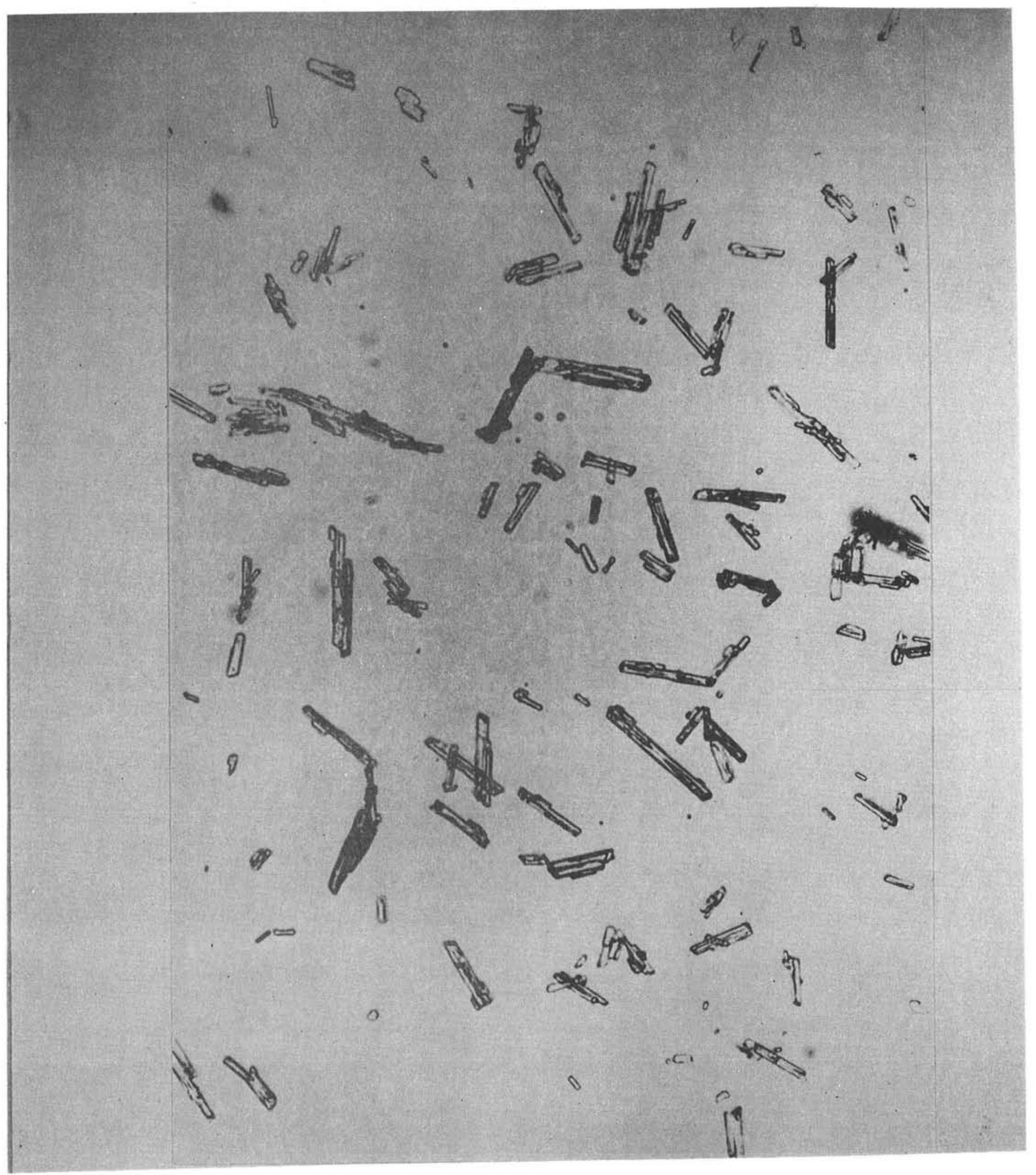

Figure I-8 RR5K PETN Lot 1377 


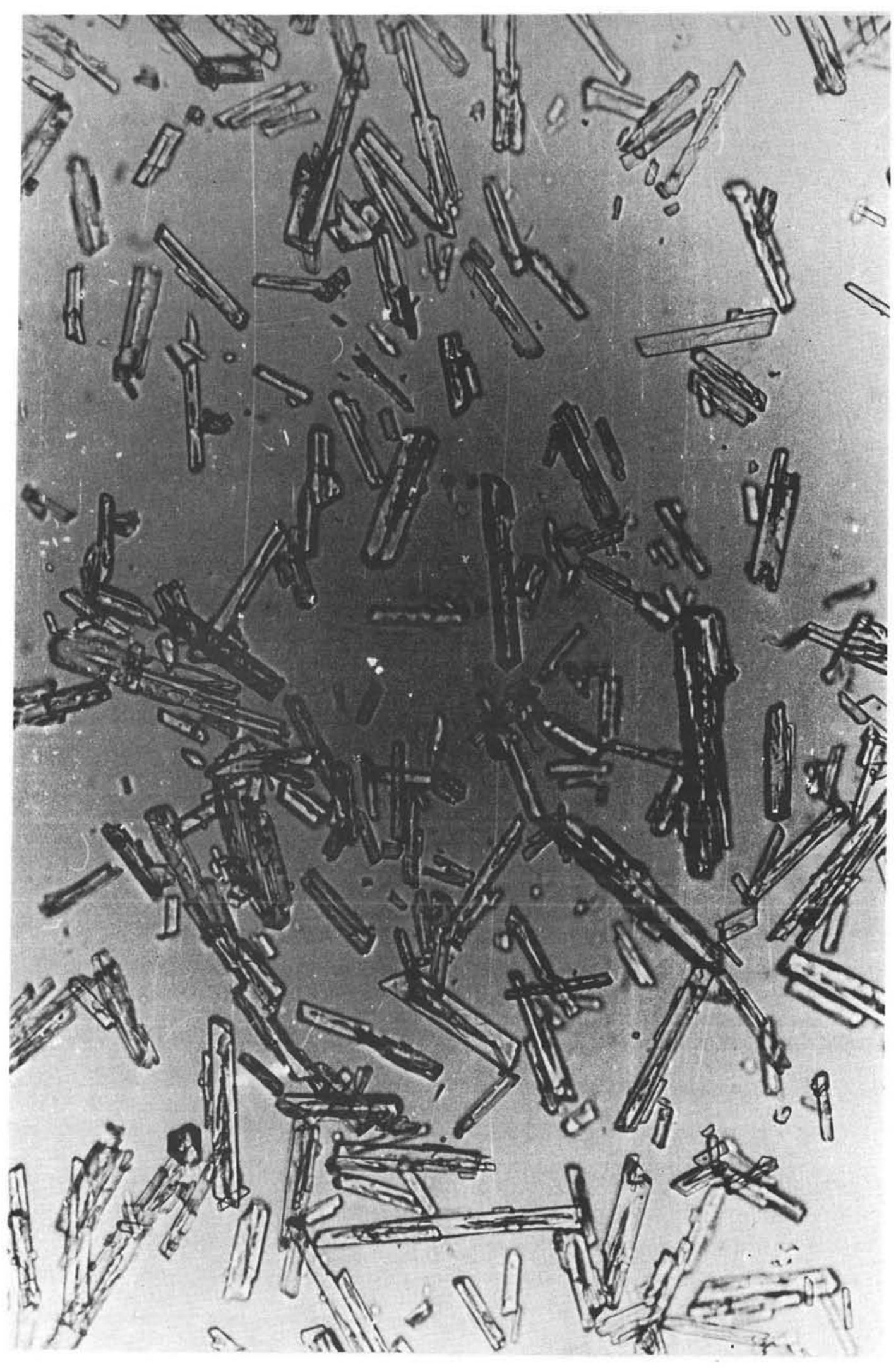

Figure I-9 RR5K PETN Lot 1378 


\section{Dependence of FSSS Results on 0perating Procedure}

A puzzling observation from this study was the difference in reported FSSS surface areas and diameters on the same lot of material depending on whether the measurements were made at Mound Facility or Pantex.

In order to ascertain why FSSS surface areas and diameters on the same material seem to be operator dependent, a small study was conducted to determine how these measurements are influenced by sample weight (Figs. II-1 through 3), round-off error of the crystal density in the calculations (Fig. II-4), and preparation of the powder column (Fig. II- 5).

A $5 \mathrm{mg}$ error in weight can change the porosity by $0.4 \%$, the surface area by $1 \%$, and the average particle diameter by $1 \%$. Using a rounded value for the crystal density 1.7700 instead of 1.7654 $\mathrm{Mg} / \mathrm{m}^{3}$ can 1 ead to a $0.5 \%$ error in the surface area. However, the largest relative error depended on whether the powder column was gent1y tapped or not before making the surface area measurements. Errors of $5 \%$ can easily be caused by differences in powder column preparation. 


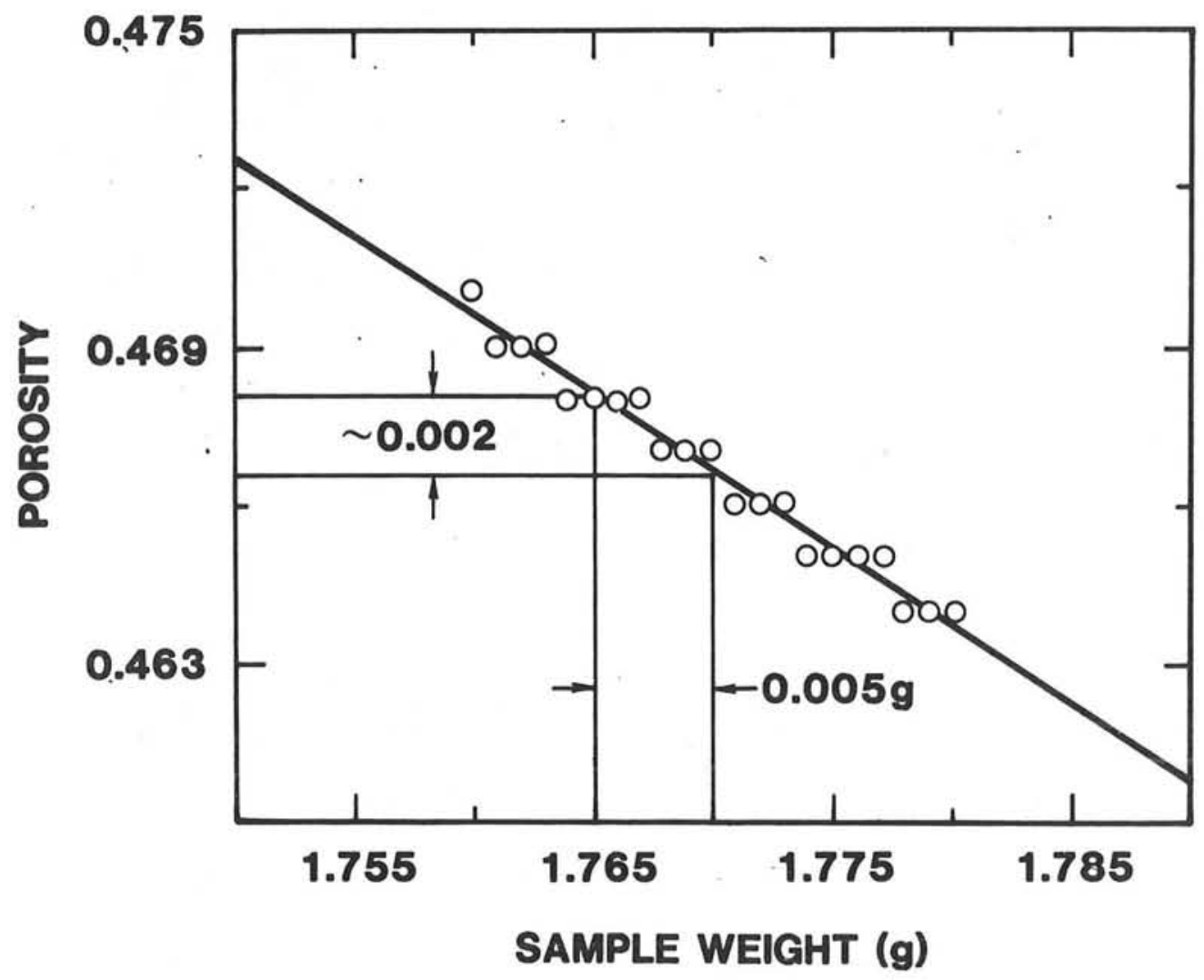

Figure II-1 Porosity vs. Sample Weight 


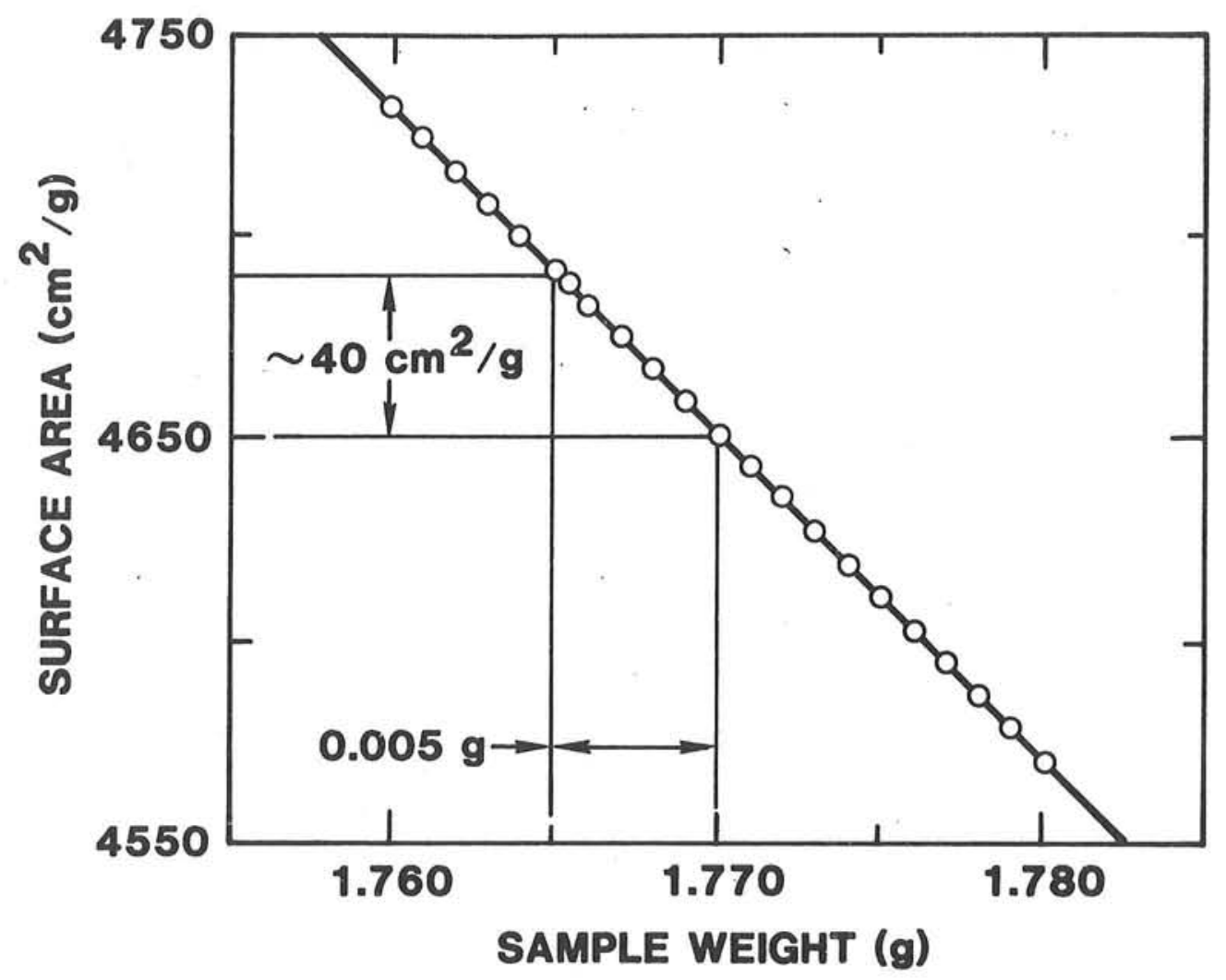

Figure II-2 Surface Area vs. Sample Weight 


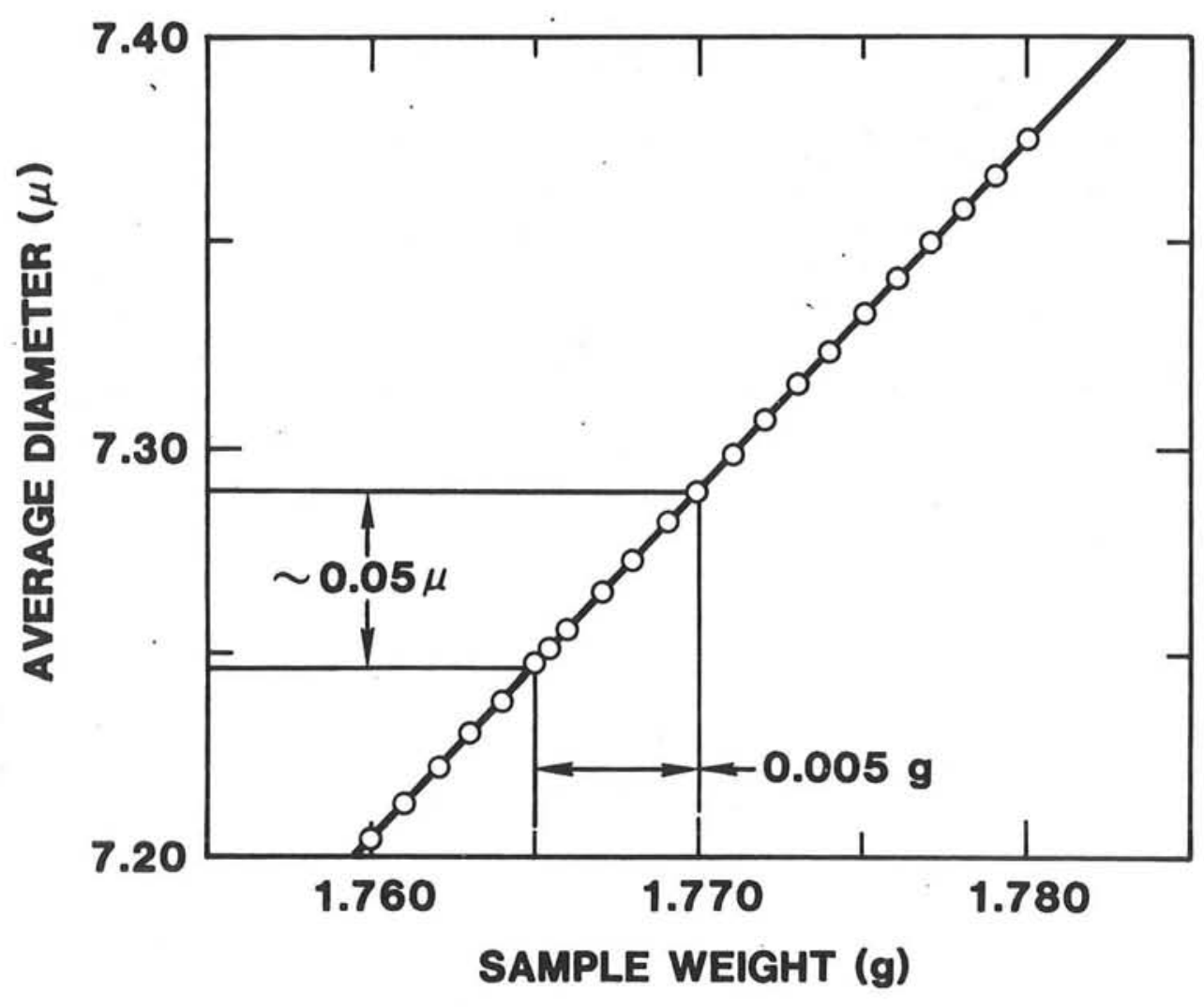

Figure II-3 Average Diameter vs. Sample Weight 


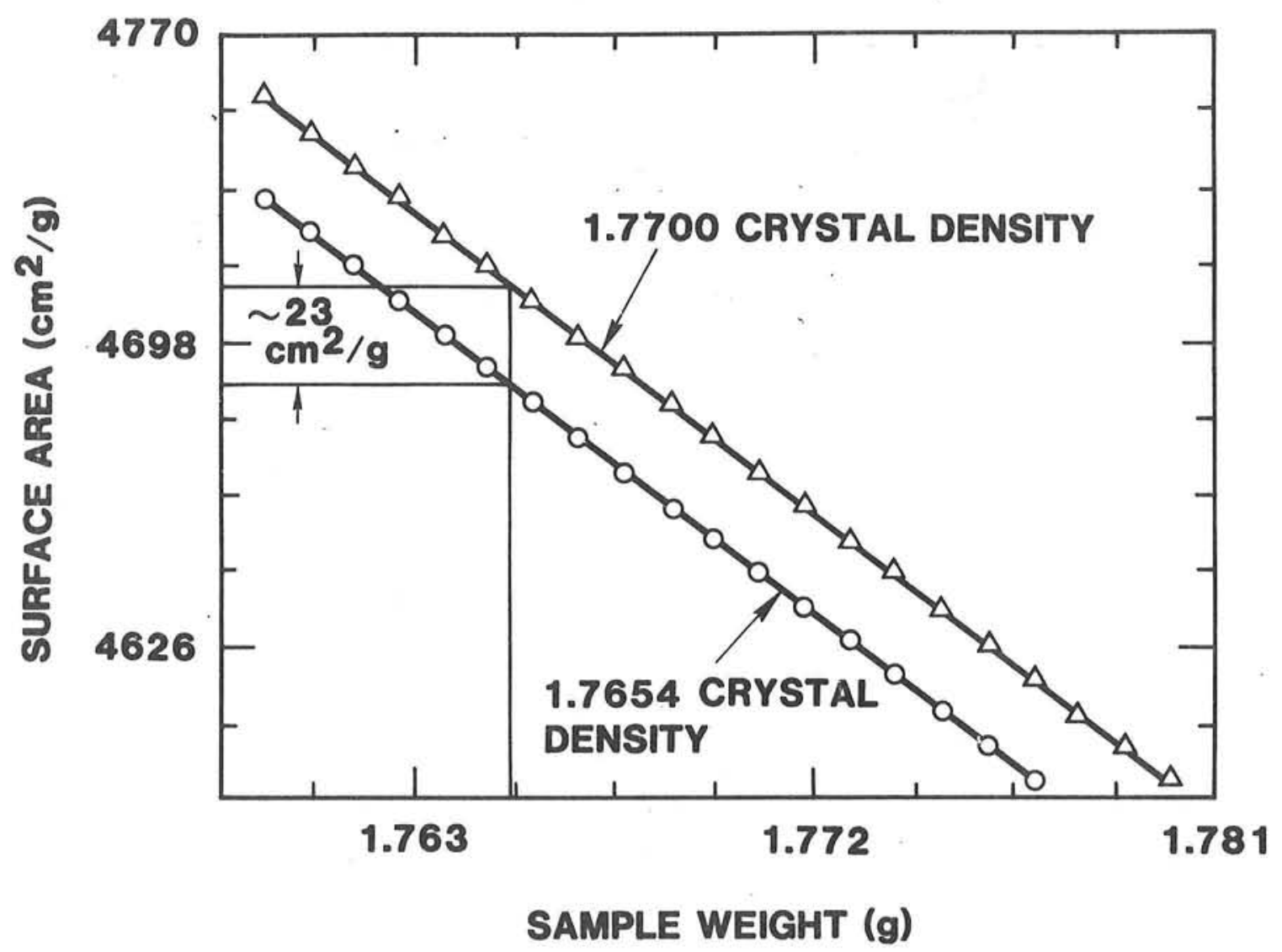

Figure II-4 Surface Area vs. Sample Weight as a Function of Crystal Density 


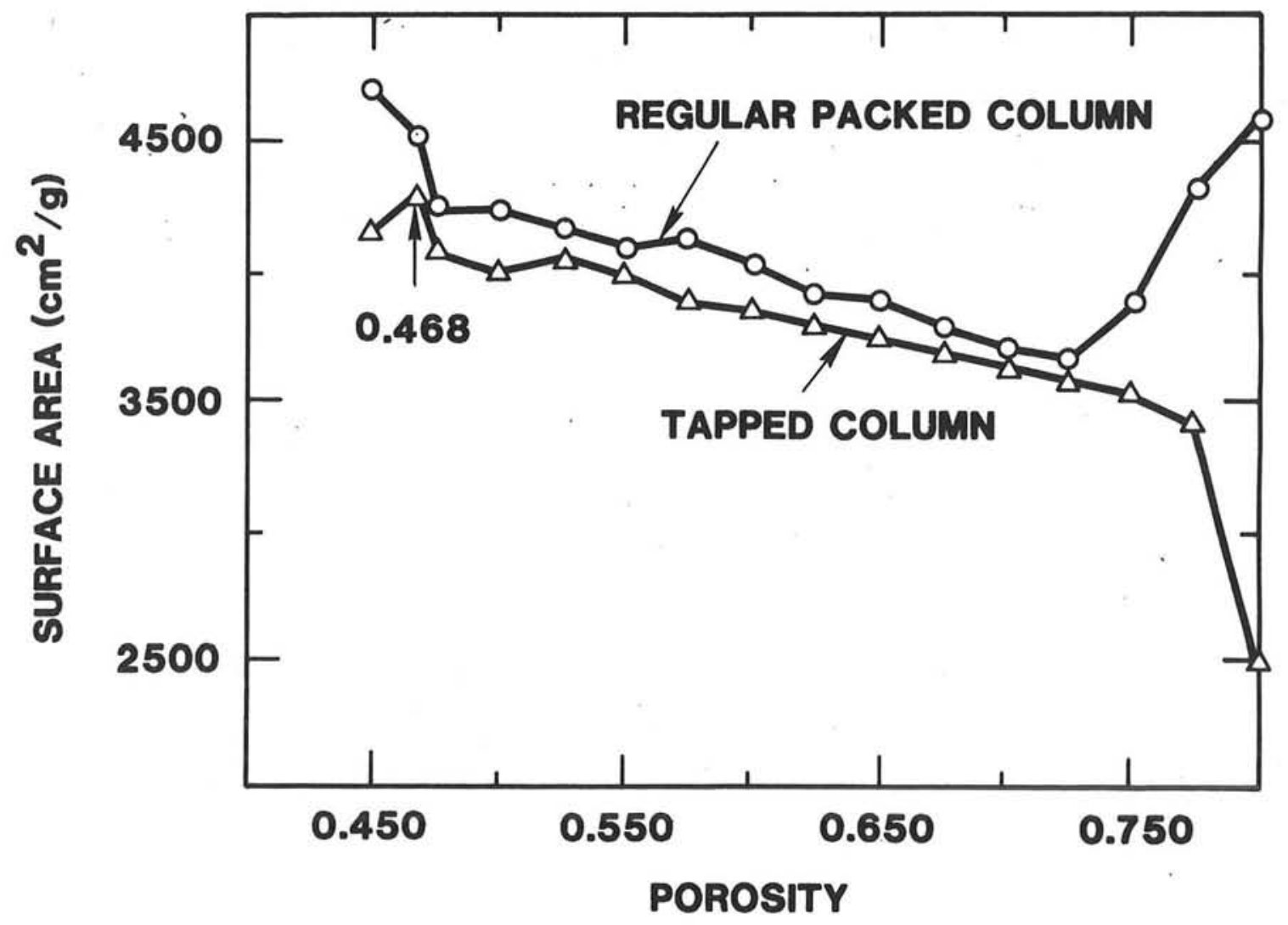

Figure II-5 Surface Area vs. Porosity 


\section{APPENDIX III}

\section{$\underline{\text { FSSS } 1 \text { and Dynamic BET } 1 \text { Results for RR5K PETN }}$}

\begin{tabular}{cccc} 
PETN Lot & $\begin{array}{c}\text { FSSS Surface } \\
\text { Area }\left(\mathrm{cm}^{2} / \mathrm{g}\right)\end{array}$ & $\begin{array}{c}\text { FSSS Average } \\
\text { Diameters }(\mu \mathrm{m})\end{array}$ & $\begin{array}{c}\text { BET Surface } \\
\text { Areas }(\mathrm{cm} 2 / \mathrm{g})\end{array}$ \\
\cline { 2 - 3 } 1159 & 4125 & 8.25 & 38905 \\
1201 & 4705 & 7.25 & 41415 \\
1204 & 4055 & 8.38 & 29370 \\
1206 & 4488 & 7.55 & 14545 \\
1258 & 4295 & 7.90 & 42625 \\
1375 & 4478 & 7.60 & 42385 \\
1376 & 4530 & 7.50 & 38060 \\
1377 & 4785 & 7.10 & 57825 \\
1378 & 4825 & 7.05 & 19530
\end{tabular}

${ }^{1}$ The reported values are the average of duplicate analyses. 


\section{APPENDIX IV \\ Definition of Terms Used in Describing a Particle Distribution}

Individual particles have physical properties of size and shape. Length, width, height, volume, cross sectional area, and equivalent spherical and circular diameter are related to size and length/width ratio, degree of sphericity, and harmonic mean diameter all relate to shape. The characteristics of a single particle are usually not of practical interest; rather the characteristics of a large number of particles are studied statistically to correlate with functional properties.

A physical parameter $x_{i}$ is observed and associated with $f_{i}$, a weighting factor of occurrence or $\mathrm{w}_{i}$, a weighting factor of mass. The distribution $\mathrm{x}_{1}, \mathrm{x}_{2}, \ldots, \mathrm{x}_{\mathrm{n}}$ is defined as the population of individual parameters which are contained between the smallest and largest value in the set.

\section{Distribution Statistic}

1. Low value (Lo Val)

2. high value (Hi Val)

3. range (Rng)

4. mid-range (Mid Rng)
Symbol or Formula

$x_{1}$
$x_{n}$
$x_{n}-x_{1}$

$$
\left(x_{n}-x_{1}\right) / 2
$$

\section{Definition or Characteristic}

Smallest size measured

Largest size measured

The population of individuals which are contained between the smallest and largest sizes of a given set of values.
A value which relates to the middle of a given range of values not based on frequency or weight. 
5. mode (Mode)

6. arithmetic mean (A meaǹ)

$$
\begin{aligned}
& \bar{x}=\frac{1}{N} \sum_{i=1}^{n} f_{i} x_{i} \\
& \text { or } \\
& \bar{x}=\frac{1}{\bar{W}} \sum_{i=1}^{n} w_{i} x_{i}
\end{aligned}
$$

7. geometric mean ( $G$ mean)

$$
\bar{x}_{G}=n \sqrt{x_{1} \cdot x_{2} \cdots x_{n}}
$$

8. harmonic mean (H mean)

$$
\bar{x}_{H}=\frac{1}{N} \sum_{i=1}^{n} \frac{f_{i}}{x_{i}}
$$

A mode of a sample of size $\mathrm{n}$ is a value which occurs with greatest frequency. A mode may not exist and if it does, it may not be - unique.

Average of series of observed values where $\mathrm{N}=$ total number of observations and $!=$ total weight.

The geometric mean, which is always less than the arithmetic mean, is useful in describing log-normal distributions. In a lognormal distribution the geometric mean is more representative of the average particle size than the arithmetic mean. Powders having geometric means similar to their mode can be indicative of a log-normal distribution.

The harmonic mean is the sum of the reciprocal of the values measured divided by the total number of values recorded. Its usefulness is in comparing particle size of different methods which determine surface area. It can be shown that the specific surface area is equal to $\left(\frac{6}{\rho}\right)\left(\frac{1}{d}\right)$ where $\rho=$ density and $\mathrm{d}=$ equivalent spherical diameter. 
9. lower $25 \mathrm{th}$

quartile

(?rt 25)

10. median 50th

Q50

quartile

(Qrt50)

11. upper $75 \mathrm{th}$

Q75

quartile

(Qrt75)

12. percentile

estimate

(PctEst)

13. semi-interquartile $\quad$ $75-Q 25$ range (SemiQrt)

14. Kramer modulus

(Kra Mod)

$$
\sum_{i=1}^{n / 2} f_{i} x_{i} / \sum_{i=n / 2}^{n} f_{i} x_{i}
$$

15. median

$\underset{\text { (Med) }}{\text { deviation }} \quad \frac{1}{\bar{N}} \sum_{i=1}^{n} f_{i}\left(x_{i}-Q_{50}\right)$

16. low range from

median (Lo Med)

$$
Q_{50}-x_{1}
$$

17. high range from

median (Hi Med).

$$
x_{n}-Q_{50}
$$

18. standard deviation (Std Dev)

$$
\left[\frac{1}{N-1} \sum_{i=1}^{n} f_{i}\left(x_{i}-\bar{x}\right)^{2}\right]^{1 / 2}
$$

19. variance (Var)

$$
\frac{1}{N-1} \sum_{i=1}^{n} f_{i}\left(x_{i}-\bar{x}\right)^{2}
$$

20. coefficient of geometric variation (Co Geo Var)
The value which is greater than $25 \%$ of the measured values.

The value which is greater than $50 \%$ of the measured values.

The value which is greater than $75 \%$ of the measured values.

A measure of the central tendency of the distribution.

Quartile deviation.

Kramers modulus is a measure of uniformity for it is the ratio of the area below the median to the area above the median.

Median deviation is a measure of the dispersion of values around the median.

Range of values from smallest value to the median.

Range of values from highest value to the median.

The standard deviation is a measure of the dispersion of values around their mean.

Another measure of the dispersion of values around their mean. It is the square of the standard deviation.

A comparison of the geometric and arithmetic means. 
21'. harmonic

variation

(Har Var)

22. mean deviation (Mean Dev)

23. low range

from mean

(Lo Mean)

24. high range

from mean

(Hi Mean)

25. degree of symmetry

(Deg Sym)

26. coefficient of skewness (Co Skew)

27. momental skewness

(Mo Skew)

28. Kurtosis

flatness

(Kurt)

29. coefficient

of excess

(Co Exs)
$\sqrt{\frac{1-\bar{x}_{H}}{\bar{x}}}$

$\frac{1}{N} \sum_{i=1}^{n} x_{i}-\bar{x}$

$$
\bar{x}-x_{i}
$$$$
x_{n}-\bar{x}
$$$$
\frac{\bar{x}-M_{0}}{\sigma}
$$

$\frac{\mu_{3}}{\bar{x}^{3}}$

$\left[\frac{\mu_{3}}{\mu_{2}^{3 / 2}}\right]^{2}$

$\mu_{4} / \mu_{2}^{2}$

$\frac{\mu_{4}}{\mu_{2}^{2}}-3$
A comparison of the harmonic and arithmetic means. Both the geometric and harmonic variation describe the skewness of the distribution from the mean.

Deviation of $x_{j}$ with respect to the arithmetic mean.

Range of values from the smallest to the mean.

Range of values from the largest to the mean.

Degree of symmetry is a measure of the variation about the mean and most frequently occurring particle in the distribution.

The coefficient of skewness is the third moment about

$$
\mu_{r}=\sum_{i=1}^{n}\left(x_{i}-\bar{x}\right)^{r}
$$

the mean divided by the mean cubed. It is used to test for normality in the horizontal direction.

A symmetric distribution has a momental skewness of zero. A positive value indicates the distribution is skewed right and a negative value means skewed left.

For a normal distribution its value is 3 . A Leptokurtic (more peaked) distribution has a value greater than 3 and $a$ Platykurtic has a value less than three. .

Same as Kurtosis flatness except a normal distribution will be zero. 
Distribution:

Mound Facilty

P. 0. Box 32

Miamisburg, OH 45342

Attn: A. Atta11a

J. R. Brinkman

R. J. DeSando

J. H. Mohler

W. E. Moddeman

Los Alamos Nationa1 Laboratory

Attn: H. H. Cady, WX-2 MS 920

J. J. Dick, M-3 MS 960

R. H. Dinnegar, WX-7 MS 950
1223 C. R. C1ark

2500 J. C. Crawford

2510 D. H. Anderson

2511 J. J. Marron

2513 J. E. Kennedy

2513 J. G. Harlan

2514 B. H. Van Domelen

2515 P. D. Wilcox

2516 W. G. Perkins

2516 J. W. Rogers, Jr. (15)

3141 L. Erickson

3154-3 C. H. Dalin for DOE/TIC (unlimited release)

Mason \& Hanger, Silas Mason Co., Inc. Pantex P1ant P. 0. Box 30020 Amari11o, TX 79177

Attn: C. D. A1ley

T. W. Stul1

A. A. Duncan

Lawrence Livermore National Laboratory Attn: R. R. McGuire, MS - L234 